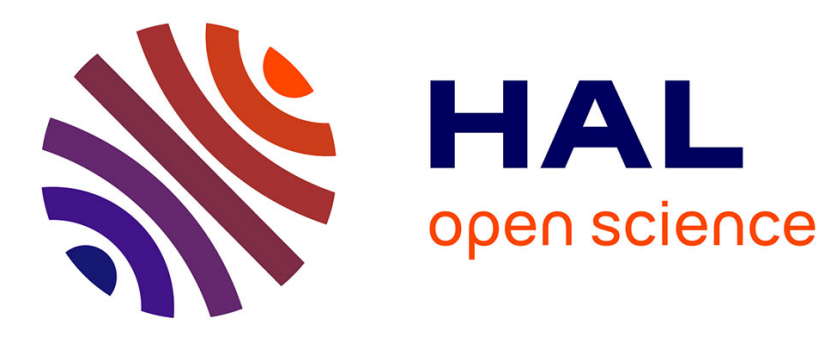

\title{
Natural catastrophe insurance: How should the government intervene?
}

Arthur Charpentier, Benoît Le Maux

\section{To cite this version:}

Arthur Charpentier, Benoît Le Maux. Natural catastrophe insurance: How should the government intervene?. Journal of Public Economics, 2014, 115, pp.1-17. 10.1016/j.jpubeco.2014.03.004 . halshs01018022

\section{HAL Id: halshs-01018022 \\ https://shs.hal.science/halshs-01018022}

Submitted on 3 Jul 2014

HAL is a multi-disciplinary open access archive for the deposit and dissemination of scientific research documents, whether they are published or not. The documents may come from teaching and research institutions in France or abroad, or from public or private research centers.
L'archive ouverte pluridisciplinaire HAL, est destinée au dépôt et à la diffusion de documents scientifiques de niveau recherche, publiés ou non, émanant des établissements d'enseignement et de recherche français ou étrangers, des laboratoires publics ou privés. 


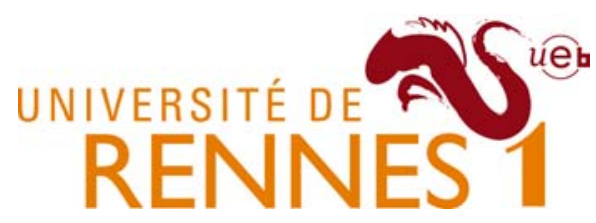

This is the author's final draft post-refeering (post-print)

Find more peer-reviewed articles on our open access repository:

http://hal-univ-rennes1.archives-ouvertes.fr/ 


\title{
Natural Catastrophe Insurance: How Should Government Intervene?*
}

\author{
Arthur CHARPENTIER \\ arthur.charpentier@univ-rennes1.fr \\ University of Rennes 1, CREM-CNRS, Ecole Polytechnique \\ Benoît LE MAUX ${ }^{\dagger}$ \\ benoit.le-maux@univ-rennes1.fr \\ University of Rennes 1, CREM-CNRS, Condorcet Center
}

Thursday $27^{\text {th }}$ March, 2014

\begin{abstract}
This paper develops a theoretical framework for analyzing the decision to provide or buy insurance against the risk of natural catastrophes. In contrast to conventional models of insurance, the insurer has a non-zero probability of insolvency which depends on the distribution of the risks, the premium rate, and the amount of capital in the company. When the insurer is insolvent, each loss reduces the indemnity available to the victims, thus generating negative pecuniary externalities. Our model shows that government-provided insurance will be more attractive in terms of expected utility, as it allows these negative pecuniary externalities to be spread equally among policyholders. However, when heterogeneous risks are introduced, a government program may be less attractive in safer areas, which could yield inefficiency if insurance ratings are not chosen appropriately.

JEL-Classification: G22, G28, H11, H84

Keywords: Insurance, Natural Catastrophe, Externalities, Government Intervention, Strong Nash Equilibrium.
\end{abstract}

\footnotetext{
${ }^{*}$ The authors would like to thank Martin Boyer, Nathalie Colombier, Ujjayant Chakravorty, Andrew Clark, Patrick Gonzalez, Marc Henry, Francesco Lagona, Fabien Moizeau, Fabio Padovano, Yvon Rocaboy, Harris Schlesinger, Dan Silverman and two anonymous referees for their valuable comments. The authors would also like to express their gratitude to the Geneva Association and the ICER for financial support. Earlier versions of this paper were presented at the PEARL seminar (VATT, Finland, 2013), the Second World Congress of the Public Choice Societies (Miami, USA, 2012), the Annual Meeting of the 'Société Canadienne de Science Economique' (Sherbrooke, Québec, 2011), Université Laval (Faculty of Business Administration, Québec, 2011), HEC Montreal (Inter-University Centre on Risk, Economic Policies, and Employment, 2010) and the University of Rennes 1 (Faculty of Economics, Rennes, 2009).

${ }^{\dagger}$ Corresponding author: Benôt Le Maux, University of Rennes 1, 7 Place Hoche, 35065 Rennes Cedex, France. E-mail: benoit.le-maux@ univ-rennes1.fr. Tel: + 332232335 67. Fax: + 33223233599.
} 


\section{Introduction}

Many scientists claim that both the frequency and strength of natural catastrophes such as hurricanes, floods and droughts have increased over the past few years (see, e.g., IPCC, 2007). Among other consequences, this growth could endanger the viability of the insurance and reinsurance industry. Not only have global weather-related insurance losses from large events escalated from a negligible level in the 1950s to an average of $\$ 9.2$ billion per year in the 1990s (Mills et al., 2001), but there have also been an increasing number of insolvencies: between 1969 and 1998, 36 US insurers became insolvent, primarily as a result of catastrophe losses. Of these companies, 20 became insolvent between 1989 and 1993, the same time period as Hurricane Hugo (Matthews, 1999). Between 2004 and 2011, 27 insurers became insolvent after the series of hurricanes that devastated Florida in 2004 and 2005 (Florida TaxWatch Research Institute, 2011). The present paper aims to investigate these failures by developing a model of the natural-catastrophe insurance market, and evaluating the ways in which the government can intervene. Two key issues will be addressed.

First, one common characteristic of public programs is that the government must strike a balance between the goal of ensuring zero default risk and the demand for limited tax exposure. ${ }^{1}$ The resulting debate generally revolves around one single question: Should taxpayers have a preference for government intervention? On the one hand, with a purely private market only policyholders at risk are faced with their insurer's insolvency. On the other hand, with a government program, policyholders participate in collective risk-sharing via tax revenues. In both cases, when the insurer is insolvent, each loss generates a negative pecuniary externality in terms of either a lower indemnity or higher taxes. To our knowledge, no formal comparative analysis of these two alternatives has been undertaken. One reason may be that a number of assumptions have to be relaxed if we wish to apply conventional insurance models to natural disasters. In particular, natural risks are correlated, so that there may be a considerable number of claims at the same time. As a result, an insurer can have a non-zero probability of insolvency depending on (1) the distribution of the risks (Kunreuther, 2001), (2) the premium rate (Tapiero et al., 1986), and (3) the amount of capital in the company (Cummins, 2006; Charpentier, 2007). The present article addresses this issue in an original theoretical framework which takes all of these dimensions into account at the same time.

Another issue regarding natural disasters is the importance of risk diversification. Large insurance companies can pool the risks with independent risks from other regions, which can significantly reduce the probability of insolvency (Cummins, 2006; Charpentier, 2007). An

\footnotetext{
${ }^{1}$ Examples of government intervention can be found in a number of countries (e.g. the US, France, Italy, Spain, Switzerland, Japan, New Zealand, Canada, Finland and Norway). In the US, the federal government and some States have developed programs for specific dangers. One example is the US flood-insurance program which has faced large accumulated deficits, as exemplified by the $\$ 810$ million deficit in the mid-1990s (Mills et al., 2001; GAO, 2007). We can also cite the CEA earthquake-insurance program which receives no money from the State budget, but does benefit from advantageous tax rules. In France, there is the "CatNat" system, where private insurance companies have the possibility to buy reinsurance from a public-policy agency, the Caisse Centrale de Réassurance. If it is not possible for this agency to pay for all the reinsured losses, it is protected by government guarantee. This came about once, in 2000, for a total amount of 457 million Euros, due to severe flooding in the South and the two storms in December 1999.
} 
insurance company can also purchase catastrophe reinsurance, which passes this risk on to reinsurers. It remains to be seen, however, whether policyholders from less risky regions will benefit from pooling with riskier regions. To address this issue, we extend our theoretical framework by focusing on a simultaneous non-cooperative game combining two regions with different natural risks.

We have two main results and policy implications. First, we show that the free market does not necessarily provide the efficient level of natural-catastrophe insurance: insurance with an unlimited guarantee from the government is shown to be a mean-preserving spread of limited-liability insurance. In simple terms, government programs allow the negative pecuniary externalities to be spread equally among policyholders; as such they are less risky and more attractive in terms of expected utility. Risk-averse policyholders will therefore accept to pay higher rates for unlimited-guarantee insurance, which will lead to a lower probability of insolvency. Second, given the pecuniary externalities one region may impose on another, we show that the viability of any government program depends strongly on the correlation between and within the regional risks. In particular, government programs may be more attractive to areas with highly-correlated risks, leading to inefficiency if insurance ratings are not chosen appropriately.

The remainder of the paper is organized as follows. Section 2 relates the main assumptions of the article to those in the existing literature. Section 3 develops the oneregion model, and Section 4 extends the theoretical framework to a two-region economy. Section 5 then statistically tests the robustness of the models, and Section 6 discusses the policy implications. Last, Section 7 concludes.

\section{Literature review}

Conventional models of insurance which deal with the problem of the rational purchase of coverage, such as Rothschild and Stiglitz's (1976) model of adverse selection, do not apply to natural risks for a number of reasons. The more recent literature has relaxed several assumptions to better fit the reality of insurance markets. Among these, the following five seem particularly important in the context of our analysis.

1. Natural risks invalidate the Law of Large Numbers. Standard insurance theories are based on the fundamental theorem of probability known as the Law of Large Numbers. This latter suggests that, given a sufficiently large number of policyholders who are independently exposed to loss, the share of people claiming a loss should converge toward a predictable average figure. This result no longer holds when we include natural catastrophes. Consider an insurance company whose claims are partitioned into (1) independent claims due to isolated events and (2) an accumulation of correlated claims due to natural disasters. Here it will be relatively difficult for the insurance company to predict how many losses will occur within a risk pool. A number of possible states of nature may pertain, depending on whether the natural catastrophe occurs. For this reason, natural catastrophes are often considered as uninsurable risks (Berliner, 1982). This idea of a range of possible states will be formally developed below.

2. Natural risks imply a default risk. In practice, natural catastrophes may jeopardize 
not only the insurer's solvency, but also financially threaten the policyholders whose claims cannot be paid fully. Only few contributions have directly considered the effect of default risk on the demand for and supply of insurance (see Tapiero et al., 1986; Doherty and Garven, 1986; Schlesinger and Schulenburg, 1987; Johnson and Stulz, 1987; Doherty and Schlesinger, 1990; Kousky and Cooke, 2012). The main idea in these models is to incorporate default risk into the insurance-pricing decision and the expected utility of purchasers. Doherty and Schlesinger (1990), for example, assume that the insurer will be solvent or insolvent with some probability, conditional on the occurrence of a loss. Unfortunately, this insolvency probability is assumed to be exogenous in the model, i.e. independent of the insurance premia and the company's capital. In Tapiero et al. (1986), the default risk depends on the premium, but claims are driven by a Poisson process (as in standard actuarial models), which prevents two or more claims being made at the same time. We here seek to fill these gaps by considering endogenous insolvency probability in the context of correlated risks.

3. The natural-catastrophe insurance market is not perfectly competitive. When risks are uncorrelated, the economic capital per policy required by an insurance company approaches zero as the number of insured risks approaches infinity. This implies that insurance companies become more competitive and propose lower premia as their number of risks increases. Due to these increasing returns to scale, the insurance industry can be either a natural monopoly (Emons, 2001) or a natural oligopoly (Cummins and Zi, 1998; Sonnenholzner and Wambach, 2004; Chiappori et al., 2006). This is all the more true when the losses are correlated. In that case, some amount of capital per policy is required even as the number of risks approaches infinity (Cummins, 2006; Charpentier, 2007). Only large companies can offer catastrophe coverage, because they have easier access to capital and can pool the risk with independent risks from other regions. ${ }^{2}$ Our research here will thus also deal with monopolistic behavior (i.e. price-making insurers), contrary to Rothschild and Stiglitz (1976), for example, who focus only on competitive insurance markets.

4. Adverse-selection theories do not apply to natural risks. A number of authors have recognized that Rothschild and Stiglitz's (1976) adverse-selection theory may not be suited to the analysis of natural-catastrophe insurance. The reason is that information asymmetry could be the other way around, so that insurers are better informed about catastrophe risks than are individuals (Kunreuther, 1984; Jaffee and Russell, 1997). Insurance companies have access to information using predictive and risk-spreading techniques to rate catastrophe exposure, while individuals' probabilities regarding high-loss/low-probability events may be distorted. We will therefore not include theoretical aspects of adverse selection in the present analysis.

5. Moral hazard and time inconsistency. Government programs may create significant moral-hazard problems by (1) discouraging individuals and local governments in regions at risk from taking protective measures (Kunreuther, 2006; Goodspeed and Haughwout, 2012) or (2) encouraging construction in hazard-prone areas (Kunreuther, 2006, Wildasin, 2008). To some extent, these behaviors can be observed even when insurance is not available. For instance, people will locate in risky areas if they consider that the government has a time-

\footnotetext{
${ }^{2}$ Consider the example of Florida, where 11 small insurance companies, with insufficient reserves and/or reinsurance cover filed for bankruptcy the year that Hurricane Andrew struck, leaving the Florida State Guaranty Fund to pay claims (The Congress of the United States, 2002).
} 
inconsistency problem, i.e. the government will likely bail people out after the occurrence of a natural disaster. To solve these problems, some authors have advocated the use of wellenforced building codes and land-use regulations to control development in hazard-prone areas (Litan, 2005; Kunreuther, 2006). To simplify the analysis, the present research will assume that such regulations are implemented, which allows us to consider an exogenous distribution of catastrophic risks.

To sum up, our assumptions will depart from the existing literature in multiple directions (correlated risks, an endogenous probability of insolvency and monopolistic market structure). These innovations will allow us to compare limited-liability insurance to a government program with unlimited guarantee.

\section{The one-region model}

Consider a region with $n$ inhabitants. This region is exposed to natural events that will cause a loss $l$ to $N$ individuals. Following the idea that the Law of Large Numbers does not apply, several states of nature can be observed (Feature 1 in the literature review above). The focus is on the share of population claiming a loss, $X=\frac{N}{n}$, which is defined over the interval $[0,1]$. Two elements determine the distribution of $X$ : first, the probability $p$ that each individual claim a loss and, second, the correlation $\delta$ between the individual risks. The coefficient $\delta$ can be said to determine the magnitude of natural catastrophes - reflecting the total number of people who claim a loss at the same time - and in turn influences the chances that the insurance industry become insolvent. The probability $p$ represents the odds for each individual of being one of the victims.

The probability of an event of size $X$ is given by the following increasing continuous distribution:

$$
F=F(x \mid p, \delta)=F(x)=\int_{0}^{x} f(t) d t \in[0 ; 1],
$$

with:
(i) $\int_{0}^{1} x f(x) d x=p$,
(ii) $\frac{\partial F}{\partial p}<0 \quad \forall x \in[0 ; 1]$,
(iv) $\frac{\partial F}{\partial \delta}<0 \quad \forall x>x^{*}$,
(v) $\frac{\partial f}{\partial \delta}>0 \quad \forall x>x^{*}$,
(iii) $\frac{\partial f}{\partial p}>0 \quad \forall x>x^{*}$,
(vi) $\frac{d p}{d \delta}=0$,

where any $x>x^{*}$ characterizes an extreme event. Assumptions (i-vi) may be interpreted as follows. (i) The chance that I claim a loss is directly related to the number $N$ of losses in the population. Consequently, the probability $p$ is also the expectation of $X$. (ii and iv) The higher the probability $p$ and the correlation $\delta$, the greater the occurrence of extreme events. (iii and v) Heuristically, the probability of an event $x$ increases with $p$ and $\delta$ if $x>x^{*}$. (vi) A change in $\delta$ has no effect on $p$. Section 5 proposes some intuitive illustrations of such a distribution function. ${ }^{3}$

\footnotetext{
${ }^{3}$ A simple way of understanding these concepts is to consider a nationwide coin-flipping game. Let $X$ denote the share of tails in the economy. If all inhabitants play with their own coin, the probability of getting tails will be $\mathrm{p}=50 \%$ for each individual, and we will expect an equal distribution of heads and tails in the economy
} 
By extreme events, we mean any event affecting a significant share of the population: $x$ larger than a given $x^{*}$. The value of $x^{*}$ is exogenous and is assumed to be determined by the shape of the distribution function itself. In practice, extreme events are more likely to take place when natural disasters (e.g., earthquakes, floods or droughts) hit the economy. Natural disasters provoke a great number of losses at the same time, which are highly correlated, and increase the probability that an individual be a victim. There is thus a relationship between $x^{*}, p$ and $\delta$. Extreme events are more likely to occur when the individual risk is high (Assumptions ii and iii regarding $p$ ) or highly correlated (iv and v related to $\delta$ ). ${ }^{4}$

For simplicity of exposition, inhabitants are considered to be strictly identical with the same preferences $U=U(Y)$, where $Y$ denotes a negative random loss that depends on the state of nature. The function $U$ is assumed to be differentiable and increasing, with $U(0)=0$. The region's inhabitants decide simultaneously whether to purchase full insurance coverage so as to maximize their expected utility.

\subsection{The supply of insurance}

Insurance coverage is provided by a single company. Following Einav et al. (2010), we take the characteristics of insurance contracts as given: only the contract price is determined endogenously, not the coverage offered. We are interested in the per capita asset value of the company $\alpha+c$, where $\alpha$ denotes the premium inhabitants have to pay and $c$ is shareholder capital per policy (see, e.g., Zanjani, 2002 or Zhang, 2008 for similar treatments). The insurer becomes insolvent when it is not possible to pay the full coverage $l$ to victims, i.e. when total losses $(\mathrm{Nl})$ are greater than total revenue $(n \alpha)$ plus total economic capital $(n c)$. The probability of insolvency is given by:

$$
\mathbb{P}(N l>n \alpha+n c)=\mathbb{P}\left(X>\frac{\alpha+c}{l}\right)=1-F(\bar{x}),
$$

where $\bar{x}=(\alpha+c) / l$ denotes the largest possible event without default. In comparison with Doherty and Schlesinger (1990), this probability is not exogenous (Feature 2 in the literature review). The greater the premium and capital per head, the higher is $\bar{x}$ and the lower the probability of insolvency. For a given value of $c$ and $\alpha$, this probability increases with $\delta$. Consequently, as in Cummins (2006), the amount of equity capital needed per risk to achieve a given insolvency target increases with the covariance among risks.

The insurance company is assumed to choose the premium $\alpha$ so as to maximize expected profit. Without insolvency, profit equals total revenue $(n \alpha)$ minus the total losses

(Assumption i). On the contrary, if they all bet on the toss of a single and unique coin, the nationwide outcome will be either only tails or heads, while the individual probability of having tails will still be $p=50 \%$. The number of coins in such a game is an inverse proxy for how the risks are correlated. Whatever the number of coins in the economy, we will always have $p=50 \%$ (Assumption vi). The occurrence of extreme events, e.g., $x>80 \%$, rises as the number of coins falls (iv and v). If inhabitants play with loaded coins, e.g., $p=70 \%$, we will expect more tails (ii and iii).

${ }^{4} \mathrm{~A}$ larger correlation between risks should also be associated with more small events, i.e. $\frac{\partial F}{\partial \delta}>0$ for low values of $x$. This assumption is however not necessary for our analysis. 
Table 1. Comparison of final payoffs. ${ }^{a}$

\begin{tabular}{lc|c|c|c}
\hline \hline & \multicolumn{2}{c}{$\begin{array}{c}\text { Individuals not claiming a loss } \\
\text { (with probability } 1-p \text { ) }\end{array}$} & \multicolumn{2}{c}{$\begin{array}{c}\text { Individuals claiming a loss } \\
\text { (with probability } p \text { ) }\end{array}$} \\
\hline & Insurance & No insurance & Insurance & No Insurance \\
\hline Limited liability & $-\alpha$ & 0 & $-\alpha-l+I(X)$ & $-l$ \\
Unlimited guarantee & $-\alpha-T(X)$ & 0 & $-\alpha-T(X)$ & $-l$ \\
Zero probability of insolvency & $-\alpha$ & 0 & $-\alpha$ & $-l$ \\
\hline \hline
\end{tabular}

${ }^{a}$ Tax $T$ is only paid if there is insufficient premium revenue to cover claims, i.e., when $X>\bar{x}$. Otherwise, $T(X)$ and $-l+I(X)$ are equal to zero.

claimed by the insured $(N l=x n l)$. Profit here can be positive or negative depending on the size of the losses. On the other hand, with insolvency, the company is assumed to distribute the capital equally to the victims, so that profit is always negative and equals $-c n$. Expected profits can be written as:

$$
\Pi(c, \alpha, p, \delta)=\int_{0}^{\bar{x}}[n \alpha-x n l] f(x) d x-[1-F(\bar{x})] c n .
$$

The company will provide insurance if and only if $\Pi(c, \alpha, p, \delta)>0$. It can be shown that greater economic capital $(c)$ reduces expected profits $(\Pi)$ (see Proposition 1). For a given premium, the insurance company is better off without any capital as only total revenue ( $n \alpha$ ) can be lost in that case. On the other hand, the higher is capital per head, the more the shareholders are exposed to failure.

Profits $\Pi$ rise with $\alpha$. As such, maximizing expected profits with respect to $\alpha$ is equivalent to minimizing the probability of insolvency (in Equation 3, greater $\alpha$ leads to higher $\bar{x}$ and lower $1-F(\bar{x})$ ). We can therefore focus equivalently on a risk-neutral insurance company which maximizes expected profits or a risk-averse company that minimizes the probability of insolvency.

Proposition 1. From expected profits $\Pi$, we obtain the following comparative static derivatives (for $\bar{x} \in[0 ; 1]$ ):

$$
\frac{\partial \Pi}{\partial c}<0, \quad \frac{\partial \Pi}{\partial \alpha}>0 .
$$

Proof. See the Appendix. 


\subsection{The demand for insurance}

Inhabitants' payoffs are set out in Table 1. These depend on whether insurance coverage comes from an insurance company with limited liability or with an unlimited guarantee from the government. Following Feature 5 in the literature review, we assume that implicit regulations prevent moral-hazard and time-inconsistency problems, so that the distribution of the risks is exogenous to the insurance decision.

The scenario with limited liability. The payoffs are determined by both the decision to buy insurance and the probability of loss $l$. If an individual does not claim a loss, the payoff is $-\alpha$ with insurance, and 0 without it. If an individual does suffer a loss, the payoff is $-\alpha-l+$ $I(X)$ with insurance and $-l$ without, where $I(X)$ represents the indemnity. Figure 1 provides an illustration. If the insurer is not insolvent $(X \leq \bar{x})$, the indemnity fully covers the loss, i.e. $I(X)=l$. In contrast, in the case of insolvency $(X>\bar{x})$, the indemnity received by each victim is equal to the total economic capital $(n c)$ plus the company's revenue $(n \alpha)$, divided by the number of policyholders claiming a loss, i.e., $I(X)=\frac{c+\alpha}{X}<l$. Each loss reduces the amount of the indemnity available, thus generating a negative pecuniary externality for the victims. The expected utility of a policyholder can be written as:

$$
V(c, \alpha, p, \delta)=\int_{0}^{1} x U(-\alpha-l+I(x)) f(x) d x+\int_{0}^{1}(1-x) U(-\alpha) f(x) d x,
$$

where the first integral represents expected utility conditional on the probability $x$ of being one of the victims. In this case, the risk of a reduced coverage, i.e. $-l+I(x)$, has to be taken into account. The second integral represents expected utility conditional on the probability $(1-x)$ of no loss. Given the properties of $F$ (Equation 2), this integral equals $(1-p) U(-\alpha)$, i.e. a policyholder will lose only $\alpha$ with a probability $1-p$.

The scenario with an unlimited guarantee. In the case of insolvency $(X>\bar{x})$, the government will ask all policyholders to pay an additional tax $T(X)$ in order to cover the payment default, i.e. $T(X)=X[l-I(X)]=X l-\alpha-c$. Each loss increases the tax, thus generating a negative pecuniary externality not only for the victims, but also for all of the other policyholders. Compared to the limited-liability scenario, this negative externality will be lower for the victims. If the insurer is not insolvent $(X \leq \bar{x})$, policyholders will not pay any tax, i.e. $T(X)=0$. Figure 1 provides an illustration. The final payoff is always $-\alpha-T(X)$, and expected utility becomes:

$$
V(c, \alpha, p, \delta)=\int_{0}^{1} U(-\alpha-T(x)) f(x) d x .
$$

For comparison purposes, standard insurance theory presupposes a zero probability of insolvency, which avoids any problem of negative externalities. In our setting, this corresponds to the situation where $I(X)$ always covers the loss $l$. In this case, policyholder expected utility is $p U(-\alpha)+(1-p) U(-\alpha)$, which is necessarily higher than $V(c, \alpha, p, \delta)$ in Equations 5 and 6 (see the third row of Table 1 for a comparison of the payoffs). The presence of default risk is thus detrimental to policyholders.

Formally, it can be shown that a fall in $c$ and a rise in $\delta$ and $p$ will reduce $V$ (see 


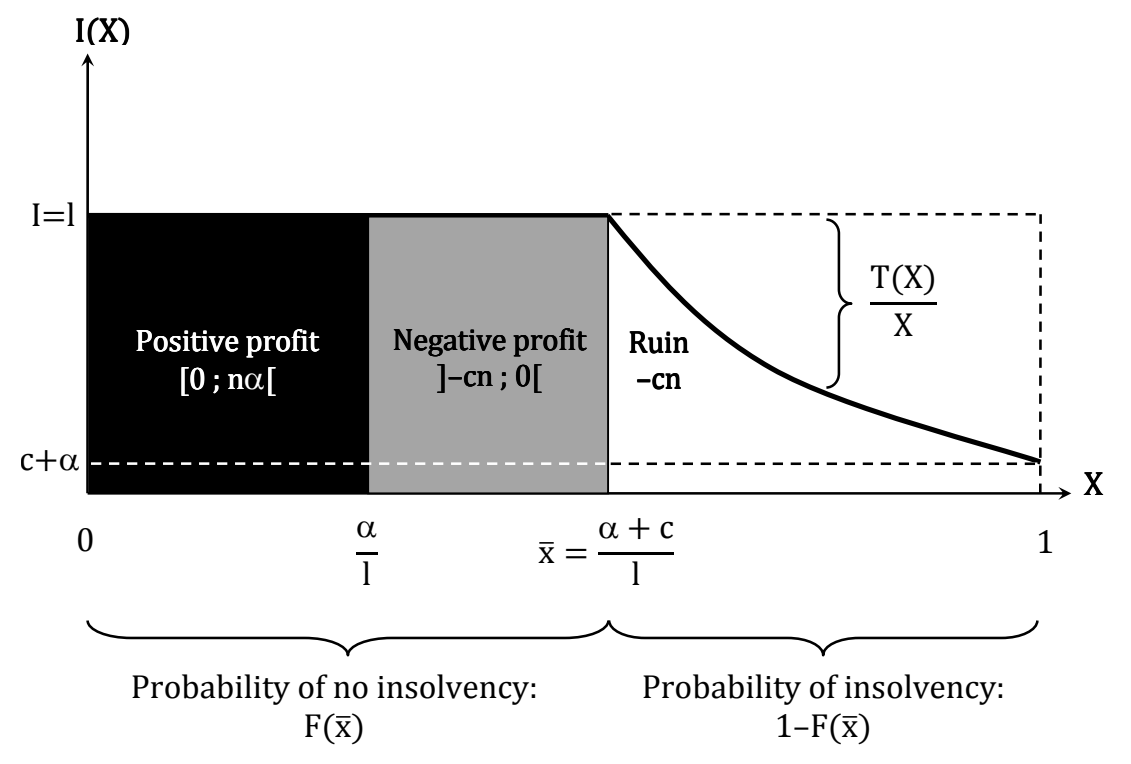

Figure 1. Relationship between indemnity $I$, profit $\Pi$ and tax $T$.

Proposition 2). In addition, the premium has a negative impact on $V$, with one exception, however, in the limited-liability scenario: if $U$ is concave (i.e., inhabitants are risk-averse), an inflection point may exist with low $\alpha$ and a high probability of insolvency $(\bar{x}<\hat{x}$, where $\hat{x}$ denotes the inflection point). In this case, policyholders will benefit from a higher premium since this will significantly reduce the probability of insolvency.

Proposition 2. From the expected utilities $V$, the one-region model leads to the following comparative-static derivatives:

$$
\begin{aligned}
\text { Both scenarios: } & \frac{\partial V}{\partial c}>0 \text { for } \bar{x} \in[0 ; 1], \frac{\partial V}{\partial \delta}<0 \text { and } \frac{\partial V}{\partial p}<0 \text { for } \bar{x}>x^{*}, \\
\text { Limited liability: } & \frac{\partial V}{\partial \alpha} \lessgtr 0 \text { for } \bar{x} \gtrless \hat{x}, \text { if } U \text { concave, } \\
\text { Unlimited guarantee: } & \frac{\partial V}{\partial \alpha}<0 \text { for } \bar{x} \in[0 ; 1] .
\end{aligned}
$$

Proof. See the Appendix.

To simplify the analysis, we will only consider symmetric equilibria. Without insurance, expected utility is $p U(-l)+(1-p) U(0)=p U(-l)$. Individuals consequently buy insurance if and only if $V(c, \alpha, p, \delta) \geq p U(-l)$.

Due to the nature of the problem, relaxing symmetry is not straightforward. For instance, say that a group of $m$ agents have bought insurance. The decision of another individual to join this group will depend on the expected indemnity $I$. The complexity comes from the fact that the expectation of $I$ is no longer a function of $F(X)$, but will rather depend on the distribution of risks in the group. This makes the model much more complicated with, 
to an extent, a structure identical to that in the two-region model presented in Section 4 (one region for the $m$ insured agents and another for the other $n-m$ agents), but with a larger set of distribution functions. Despite this difficulty, it should be stressed that increasing the size of the risk pool is a traditional approach to insurance financing, even for natural catastrophes (see Cummins, 2006 and Appendix A.8). Put simply, the insurance industry benefits from positive externalities. In the same region, if an individual is better off by joining a group of $m$ insured agents, this would also apply to the other (identical) individuals since the probability of default will be lower. We therefore expect only two possible outcomes: "no-one is insured" or "everyone is insured".

Assuming positive externalities is not sufficient to guarantee a unique Nash equilibrium. When no-one is insured, there is no incentive for a single agent to buy insurance coverage since he/she would pay a premium without reducing his/her risk. In other words, the concept of Nash equilibrium is not suitable. Individuals can become stuck in a non-optimal equilibrium where insurance does not exist even though it is the best solution. To overcome this issue, we appeal to the concept of strong Nash equilibrium in pure strategies. A strong Nash equilibrium is immune to any group deviation and, as such, is a much stronger concept than Nash equilibrium (Konishi et al., 1997). When positive externalities are at play, it is actually possible to show that a strong Nash Equilibrium exists, and is unique and symmetric (see Appendix A.9). For this reason, when we refer to equilibrium below, we will be assuming that it is a strong Nash equilibrium. ${ }^{5}$

Let $\alpha^{*}$ denote the maximum premium individuals are willing to pay for an insurance contract, such that $V=p U(-l)$. It can be shown that $\alpha^{*}$ increases with capital $(c)$ and falls with the correlation $(\delta)$ (see Proposition 3). The reason is that a rise in $c$ and a fall in $\delta$ reduce the probability of insolvency (from Equations 2 and 3) and increase expected utility $V$ (Proposition 2). This result is consistent with Tapiero et al. (1986), who also find a negative relationship between default risk and the premium policyholders are willing to pay.

Proposition 3. From the willingness to pay $\alpha^{*}$, the one-region model yields the following comparative-static derivatives:

$$
\frac{\partial \alpha^{*}}{\partial c}>0 \text { for } \bar{x} \in[0 ; 1], \quad \frac{\partial \alpha^{*}}{\partial \delta}<0 \text { for } \bar{x}>x^{*} .
$$

Proof. See the Appendix.

Note that the difference between the scenarios comes from the expected utility $V$ (Equations 5 and 6). Consider a given value of $X$, say $x$. Under limited liability, a policyholder will have an $x$ percent chance of being a victim with a payoff of $Y=-\alpha-l+I(x)$, and a $(1-x)$ percent chance of receiving $Y=-\alpha$. Let $A=\{-\alpha-l+I(x), x ;-\alpha, 1-x\}$ denote this lottery. With unlimited guarantees, policyholders will always receive a payoff of $Y=-\alpha-T(x)$. This lottery can be defined as $B=\{-\alpha-T(x), 1\}$. As $A$ and $B$ have

\footnotetext{
${ }^{5}$ Since we are dealing with symmetric equilibria, the decision to buy insurance is the same for all individuals in the region. Consequently, tax $T$ can be applied indifferently to "taxpayers" or "policyholders". For the sake of simplicity, we refer to our agents as "policyholders". In practice, however, policyholders could leave the program. This is why ex-post taxes are traditionally applied to taxpayers.
} 
the same mean, $A$ can be said to be the mean-preserving spread of $B$. As a result, $B$ will be preferred by all expected utility maximizers who have a concave utility function (Rothschild and Stiglitz, 1970). Note that $V$ is derived from a combination of $A$, or $B$, and a third lottery $f$. From the Independence Axiom of the von Neumann-Morgenstern Expected Utility Theory, preference over $A$ and $B$ will be unaffected by $f$. Policyholders are hence better off under government intervention, implying that their willingness to pay will be higher, as shown in Proposition 4.

Proposition 4. Ceteris paribus, expected utility $V$ is higher in the unlimited-guarantee scenario if policyholders are risk-averse. Hence, the unlimited-guarantee scenario yields a greater willingness to pay $\left(\alpha^{*}\right)$ than the limited-liability scenario.

Proof. See the Appendix.

\subsection{Market equilibria}

We first consider non perfectly-competitive markets (Feature 3 in the literature review). If the company is a price-maker, the equilibrium will be characterized by a premium such that (1) the insurance company offers catastrophe coverage to maximize expected profit (or equivalently to minimize the probability of insolvency), and (2) inhabitants choose insurance to maximize their expected utility.

As $\partial \Pi / \partial \alpha>0$ (from Proposition 1), the insurance company will choose the highest possible premium such that inhabitants buy insurance, i.e., such that $V \geq p U(-l)$, subject to the constraint that $\Pi \geq 0$. In other words, the insurer will set the premium equal to the policyholders' willingness to pay, $\alpha^{*}$. The outcome in terms of expected utility will be the same in both scenarios: each individual will obtain utility of $p U(-l)$, both with and without insurance coverage. Given Proposition 4, if inhabitants are risk-averse, the insurer will be better off with an unlimited guarantee from the government.

What is the impact of $\delta$ and $c$ in this case? Regarding $\delta$, a fall in the correlation will generate higher expected utility (from Proposition 2), which will allow the company to increase the price of the contract (Proposition 3) and yield higher expected profits (Proposition 1). The impact of capital $c$ is more ambiguous. Higher $c$ will lead to greater shareholder exposure to industry failure (Proposition 1). It will also lead to higher policyholder willingness to pay (Proposition 3) and generate an indirect increase in expected profits via the premium $(\partial \Pi / \partial \alpha>0$ in Proposition 1). A company's decision to provide insurance coverage for natural risks therefore depends on both the capital requirements and the sensitivity of demand to insurers' financial strength. With inelastic demand, insurance companies will be better off without any capital requirements. On the contrary, with elastic demand a large company may earn higher expected profits as capital increases.

Our results can be easily extended to a price-taking insurance company. The optimal choice from the point of view of policyholders is that with the lowest premium, so that expected utility $V$ is maximized subject to the constraint that the industry faces positive expected profits (or an insolvency probability which is sufficiently low in the case of a riskaverse company). This optimum can be reached via either market regulation (if policy-makers 
Table 2. Pecuniary externalities in the two-region model. ${ }^{a}$

\begin{tabular}{lllll}
\hline \hline Region 1 & Region 2 & $\begin{array}{l}\text { Probability } \\
\text { of insolvency }\end{array}$ & $\begin{array}{l}\text { Indemnity in the case } \\
\text { of insolvency: } I(X)\end{array}$ & $\begin{array}{l}\text { Additional tax in the case of } \\
\text { insolvency } T(X)=X[l-I(X)]\end{array}$ \\
\hline Insurance & Insurance & $1-F_{0}\left(\bar{x}_{0}\right)$ & $\frac{n_{1}\left(c+\alpha_{1}\right)+n_{2}\left(c+\alpha_{2}\right)}{N_{0}}$ & $X_{0} l-\frac{n_{1}\left(c+\alpha_{1}\right)+n_{2}\left(c+\alpha_{2}\right)}{n_{0}}$ \\
Insurance & No insurance & $1-F_{1}\left(\bar{x}_{1}\right)$ & $\frac{c+\alpha_{1}}{X}$ & $X_{1} l-c-\alpha_{1}$ \\
No insurance & Insurance & $1-F_{2}\left(\bar{x}_{2}\right)$ & $\frac{c+\alpha_{2}}{X_{2}}$ & $X_{2} l-c-\alpha_{2}$ \\
No insurance & No insurance & 0 & 0 & 0 \\
\hline \hline
\end{tabular}

have sufficient information) or the market itself (if it is sufficiently competitive). Either way, policyholders will be better off with (1) government intervention (if inhabitants are riskaverse), (2) higher capital requirements (if demand is sensitive to insurers' financial-strength) and (3) a lower correlation between risks.

\section{Extension to a two-region economy}

\subsection{A new theoretical framework}

Consider now an economy composed of two populations $n_{1}$ and $n_{2}$ living in two different jurisdictions, denoted by Region 1 and 2, respectively. Each region is exposed to natural events which cause losses of $l$ to $N_{i}$ inhabitants in Region $i, i=1,2$. We are interested in the stochastic process $\left(X_{1}, X_{2}\right)$, with $X_{i}=N_{i} / n_{i} \in[0 ; 1]$. The share of people claiming a loss in the total population is denoted by $X_{0}=\frac{N_{1}+N_{2}}{n_{1}+n_{2}}$. The states of nature are based on the following probability distributions:

$$
\begin{aligned}
& X_{1} \sim F_{1}\left(x_{1} \mid p, \delta_{1}\right)=F_{1}\left(x_{1}\right), \\
& X_{2} \sim F_{2}\left(x_{2} \mid p, \delta_{2}\right)=F_{2}\left(x_{2}\right), \\
& X_{0} \sim F_{0}\left(x_{0} \mid F_{1}, F_{2}, \theta\right)=F_{0}\left(x_{0} \mid p, \delta_{1}, \delta_{2}, \theta\right)=F_{0}\left(x_{0}\right),
\end{aligned}
$$

where $F_{1}$ and $F_{2}$, the distributions of risk in each region, are assumed to satisfy the properties described in Equation 2. For simplicity, the probability $p$ of claiming a loss is the same in both regions. The correlation between the risks (hereafter referred to as the within-correlation), $\delta_{1}$ for Region 1 and $\delta_{2}$ for Region 2, are allowed to be different. Function $F_{0}$, the distribution of risk in the whole economy, is directly derived from $F_{1}$ and $F_{2}$. This distribution depends on a new parameter, the between-correlation $(\theta)$, which defines how risks are correlated between regions. We assume:
(i) $\frac{\partial F_{0}}{\partial p}<0 \quad \forall x \in[0 ; 1]$,
(ii) $\frac{\partial f_{0}}{\partial p}>0 \quad \forall x>x^{*}$
(iv) $\frac{\partial f_{0}}{\partial \delta_{i}}>0 \quad \forall x>x^{*}$,
(v) $\frac{\partial F_{0}}{\partial \theta}<0 \quad \forall x>x^{*}$
(iii) $\frac{\partial F_{0}}{\partial \delta_{i}}<0 \quad \forall x>x^{*}$
(vi) $\frac{\partial f_{0}}{\partial \theta}>0 \quad \forall x>x^{*}$ 


\begin{tabular}{cccc} 
& & \multicolumn{2}{c}{ Region 2 } \\
Region 1 & Insure & Insure & Do not insure \\
\cline { 3 - 4 } & Do not insure & $V_{1}\left(c, \alpha_{1}, \alpha_{2}, p, \delta_{1}, \delta_{2}, \theta\right), V_{2}\left(c, \alpha_{1}, \alpha_{2}, p, \delta_{1}, \delta_{2}, \theta\right)$ & $V_{1}\left(c, \alpha_{1}, p, \delta_{1}\right), p U(-l)$ \\
\cline { 3 - 3 } & & $p U(-l), V_{2}\left(c, \alpha_{2}, p, \delta_{2}\right)$ & $p U(-l), p U(-l)$ \\
\hline
\end{tabular}

Table 3. Payoff matrix.

for $i=1,2$. Assumptions (i-vi) may be interpreted as follows. (i, iii and v) The occurrence of extreme events in the economy increases with $p, \delta_{1}, \delta_{2}$ and $\theta$. (ii, iv and vi) Heuristically, the probability of an event $x$ increases with $p, \delta_{1}, \delta_{2}$ and $\theta$ if $x>x^{*}$.

There is no mobility between regions. Individuals only differ in their location and, therefore, in their probability distributions $\left(F_{1}\right.$ or $\left.F_{2}\right)$. The premia they pay are given by $\alpha_{1}$ and $\alpha_{2}$, respectively.

The model can be applied equally to insurance with limited liability or unlimited guarantee. In the unlimited-guarantee case, the tax is paid only by those who bought insurance. In other words, the expected utility functions are similar to those in the oneregion model (Equations 5 and 6). This implies that the limited-liability scenario remains a mean-preserving spread of the unlimited-guarantee case. The question that arises, however, is whether pooling regions is preferable to no pooling at all, and under which conditions. Table 2 illustrates the problem. When all individuals in a region are insured, this influences the probability of insolvency in the other region, as well as the indemnity received and the additional tax. As a result, willingness to pay can be favorably or unfavorably affected by risk pooling.

For the sake of simplicity, we will describe the model in terms of a two-representativeperson game. We refer to the players as Region 1 and Region 2. There are a number of reasons for using representative agents. In particular, as discussed in Appendix A.8, the insurance industry can exist only when a sufficient number of individuals buy insurance. We should therefore be interested in coalitional deviations. This can be done in three ways. First, as in Section 3, we can assume that positive externalities are in play in each region. In this case, it is possible to show that the rows of Table 2 describe the only four possible strong Nash equilibria (see Appendix A.10). Second, we can consider the equilibrium premia as resulting from the insurers' perceptions of the world. The insurance company may be assumed not to provide insurance in one region if the number of contracts is insufficient to significantly reduce the probability of insolvency. To illustrate, many insurers in the UK have refused to take on new properties with a history of flooding or charge risk-adequate premia that many potential customers will think to be too expensive (DEFRA, 2011). Third, we can view this strategic game as an interaction between two consumer unions, or elected representatives, which coordinate the actions of their agents. In any case, this leads us to consider strong Nash equilibria only. The decision to buy insurance will be the same for all individuals in the same region.

Each region has to decide simultaneously whether to buy insurance coverage. The set of actions available in Regions 1 and 2 is denoted \{Insure, Do not insure . The final payoff matrix is presented in Table 3. The first entry in each box is Region 1's expected utility for the 
corresponding strategy profile; the second is that of Region 2. If Region $j$ chooses not to take out insurance, Region $i$ 's expected utility will depend only on its own characteristics, as in the one-region model. Region $i$ will buy insurance if and only if $V_{i}\left(c, \alpha_{i}, p, \delta_{i}\right) \geq p U(-l)$. On the contrary, if Region $j$ chooses to buy insurance, Region $i$ 's expected utility will depend on both regions' characteristics: $V_{i}=V_{i}\left(c, \alpha_{1}, \alpha_{2}, p, \delta_{1}, \delta_{2}, \theta\right)$. The correlations $\delta_{j}$ and $\theta$ affect $V_{i}$ as the insolvency probability depends on $F_{0}$. The premium $\alpha_{j}$ affects $V_{i}$ as it plays a role in the insolvency probability, the indemnity and the tax (see Table 2).

Proposition 2 regarding the derivatives of $V$ will still hold if only one region buys insurance. The results can also be extended to the two-region case when both regions buy insurance: we then find a negative relationship between $V$ and each correlation (see Proposition 5).

Proposition 5. When both regions decide to buy insurance, the two-region model leads to the following comparative-static derivatives (for $i=1,2 ; i \neq j$; and for $\bar{x}>x^{*}$ ):

$$
\frac{\partial V_{i}}{\partial \delta_{i}}<0, \quad \frac{\partial V_{i}}{\partial \delta_{j}}<0, \quad \frac{\partial V_{i}}{\partial \theta}<0 .
$$

Proof. See the Appendix.

Let $\alpha_{i}^{*}$ denote the willingness to pay of Region $i$ when only Region $i$ chooses to insure. In this case, the results are strictly identical to the one-region model (Proposition 3 ). By way of contrast, if we denote by $\alpha_{1}^{* *}$ and $\alpha_{2}^{* *}$ the willingnesses to pay when both regions choose to insure, we have:

Proposition 6. When both regions decide to purchase insurance, the two-region model of natural-catastrophe insurance leads to the following comparative-static derivatives (for $i=$ 1,2 and $j \neq i$ ):

$$
\begin{aligned}
& \text { For } \bar{x} \in[0 ; 1]: \quad \frac{\partial V_{i}}{\partial \alpha_{j}}>0, \quad \frac{\partial \alpha_{i}^{* *}}{\partial \alpha_{j}}>0 . \\
& \text { For } \quad \bar{x}>x^{*}: \quad \frac{\partial \alpha_{i}^{* *}}{\partial \delta_{i}}<0, \quad \frac{\partial \alpha_{i}^{* *}}{\partial \delta_{j}}<0, \quad \frac{\partial \alpha_{i}^{* *}}{\partial \theta}<0 .
\end{aligned}
$$

Proof. See the Appendix.

Figure 2 provides an illustration of Proposition 6. The left-hand panel displays the case where Region $j$ decides not to buy insurance: only the premium $\alpha_{i}$ matters for Region $i$ 's decision to insure. On the contrary, the right-hand panel shows the case where Region $j$ decides to buy insurance. The higher the premium in Region $j$, the lower the probability of insolvency, and the higher the expected utility of Region $i$. As a result, Region $i$ is willing to pay a higher rate if Region $j$ also pays a higher rate.

\section{2. (Strong) Nash equilibria}

The set of (strong) Nash equilibria can be obtained by mixing together the bottom-left and bottom-right panels of Figure 2. Figure 3 illustrates. The dotted line represents the 45 -degree 


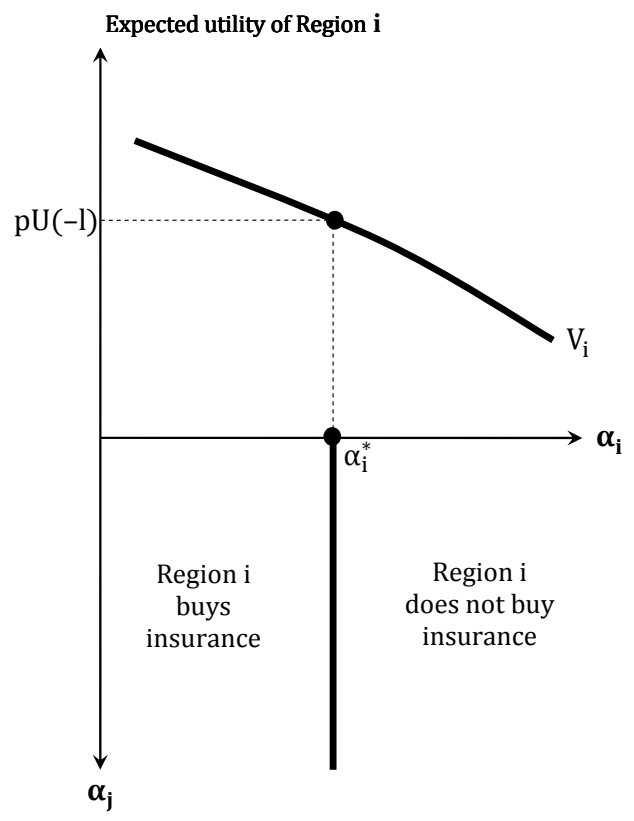

(a) If Region $\mathrm{j}$ chooses not to have insurance

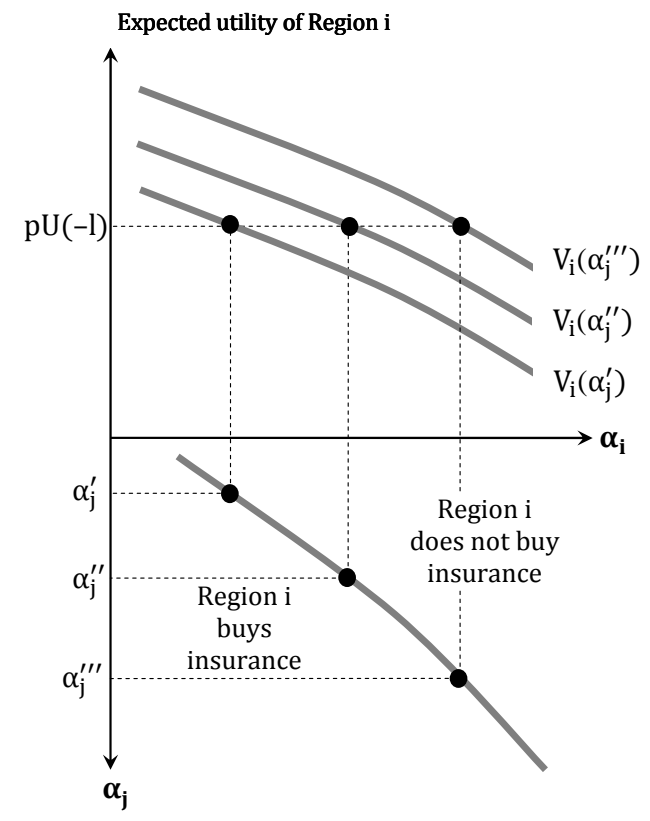

(b) If Region j chooses to have insurance

Figure 2. Illustration of Proposition 6
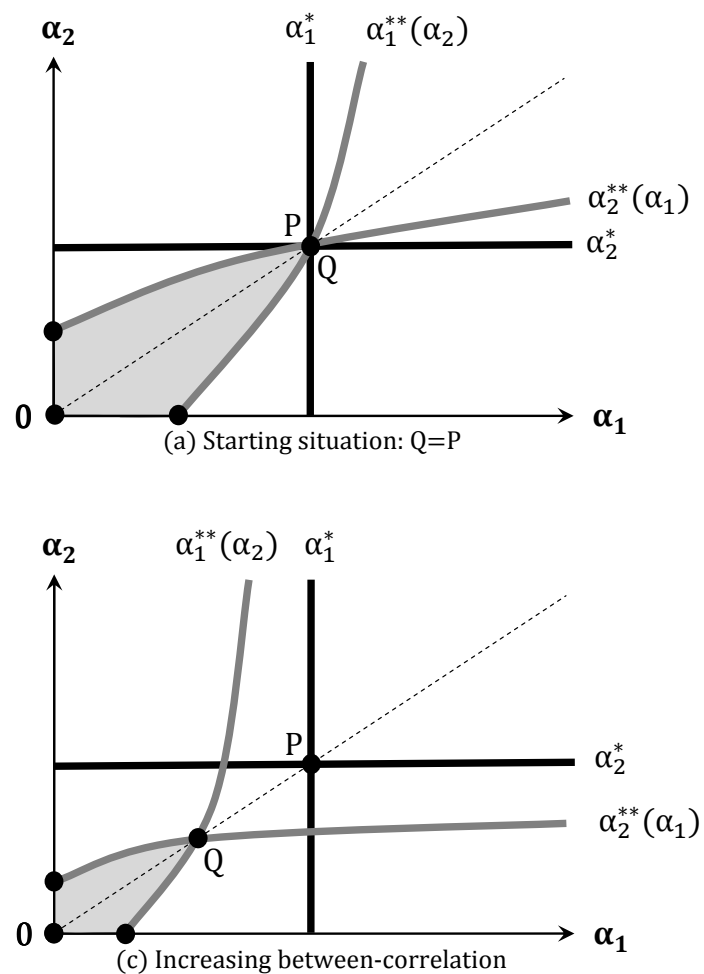

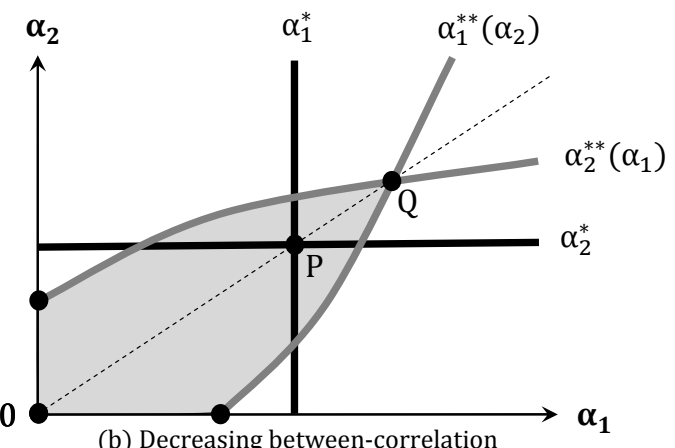

(b) Decreasing between-correlation

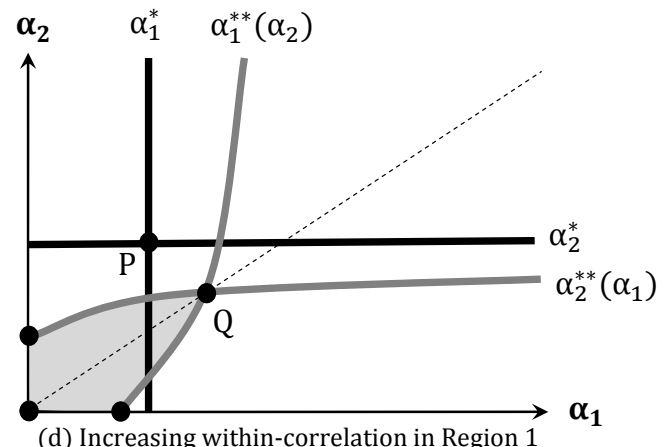

Figure 3. Set of (strong) Nash equilibria. 
line where the premia in Region 1 and Region 2 are identical. The black lines depict the willingness to pay when only one region is insured, i.e., $\alpha_{1}^{*}$ and $\alpha_{2}^{*}$. Above the $\alpha_{2}^{*}$-lines, Region 2 will not buy insurance, and neither will Region 1 to the right of the $\alpha_{1}^{*}$-lines. In other words, the intersection point $P$ between the black lines represents the willingness to pay when the regions accept insurance via two separate programs.

The grey curves represent the willingness to pay when both regions are insured, i.e., $\alpha_{1}^{* *}$ and $\alpha_{2}^{* *}$. Above the $\alpha_{2}^{* *}$-curves, Region 2 will not busy insurance, neither will Region 1 to the right of the $\alpha_{1}^{* *}$-curves. These curves are upward-sloping in the other region's premium from Proposition 6. The intersection point $Q$ between the grey curves represents the willingness to pay when the regions accept insurance via the same program.

Consider a value of $\theta$ such that Points $P$ and $Q$ are the same. This starting situation is represented in Panel $a$ of Figure 3, where the regions are assumed to be strictly identical. As a result of this symmetry, the intersection points are both on the 45-degree line and $\alpha_{i}^{* *}(0)$ is lower than $\alpha_{i}^{*}, i=1,2$. From Proposition 6, a fall in $\theta$ yields a higher willingness to pay $\alpha_{i}^{* *}$. As a result, Point $Q$ moves to the North-East of Point $P$, and the regions' willingness to buy insurance will be greater when risks are pooled (see Panel $b$ ). On the other hand, as the between-correlation increases, pooling risks will lead to a lower willingness to pay: Point $Q$ will move to the South-West of Point $P$ (see Panel $c$ ).

Panel $d$ displays an asymmetric case where only Region 1 faces an increase in the within-correlation, i.e. $\delta_{1}$ increases. From Proposition 3, Point $P$ moves to the West as we have $\partial \alpha^{*} / \partial \delta<0$ in the one-region model. On the other hand, Point $Q$ moves to the SouthWest as both Regions 1 and 2 are affected by the change in $\delta_{1}$ (Proposition 6). When both regions are insured, the players have the same expected utility function. Their willingnesses to pay are necessarily equal, which implies that Point $Q$ will remain on the 45 -degree line. As a result, Region 1's willingness to pay for insurance is higher with pooled risks, which is not the case for Region 2.

The two-region model underlines the important role of the between-correlation in insurance. In panel $c$, willingness to pay is lower when the regions are pooled together. This is because the between-correlation is sufficiently high to increase the default risk and lower the benefit from insurance. In the asymmetric case, a common program may be less attractive to safer regions. The importance of these results should not be understated. In January, 2011, a United States Representative from the State of Michigan, Candice Miller, proposed legislation aiming to end the government-run flood insurance program (H.R. 435, National Flood Insurance Program Termination Act of 2010). This bill was re-introduced as H.R. 1194 on March 14, 2013. She points out that participants in some States, such as Michigan, have to pay for and cover the costs incurred in some other States. In our model, this problem can be resolved by proposing a price that truly reflects regional within-correlation, and not only the expected loss as is usually the case.

For instance, in Panel $d$, pooling the risks from the starting Point $P$ without changing the premia has the following consequences. On the one hand, Region 1 will accept this pooling as $\alpha_{1}^{* *}$ is higher than $\alpha_{1}^{*}$; however, Region 2 will be worse off since $\alpha_{2}^{* *}$ is lower than $\alpha_{2}^{*}$. In other words, Region 1 will experience a gain in utility over the reversion level $p U(-l)$, which is not the case for Region 2. As such, at Point $P$ both regions cannot choose insurance. The 
only way to achieve pooling is by reducing the premium in Region 2 .

\section{Robustness analysis}

The present section tests the robustness of our theoretical framework via statistical modeling. There are two main techniques to incorporate correlation in a non-Gaussian context, both of which imply mixture models, i.e. probabilistic models based on several randomly-chosen distributions (see, e.g., Denuit et al., 2005). The first technique consists in using a discrete common-shock model, with a dichotomous variable describing the catastrophe occurrence. The second focuses on a frailty-type model, with a continuous variable describing the intensity of the catastrophe. We here use the first approach, which allows us to derive much simpler results. To our knowledge, common-shock models have never been used in the context of natural catastrophes and, as such, the following Sections are an innovative way of investigating the theoretical models in Sections 3 and 4.

\subsection{Modeling within-correlations}

In the one-region model, the distribution function of $N$ (or equivalently $X$ ) can be defined as a mixture model depending on three probabilities:

- $p^{*}=\mathbb{P}($ Cat $) \in[0 ; 1]$ is the probability of a natural catastrophe, with $1-p^{*}=\mathbb{P}($ No Cat $)$.

- $p_{N} \in[0 ; 1]$ is the probability that an individual claim a loss in the case of no natural catastrophe.

- $p_{C} \in[0 ; 1]$ is the probability that an individual claim a loss in the case of a natural catastrophe. We assume that $p_{C} \geq p_{N}$, i.e. natural catastrophes increases risk occurrence.

The individual probability of loss is given by:

$$
p=p_{N}\left(1-p^{*}\right)+p_{C} p^{*}
$$

Conditional on the occurrence or not of a natural catastrophe, the risks between individuals are assumed to be independent. For example, if $p^{*}=p_{N}=p_{C}=10 \%$, the probability of loss is equal to $p=10 \%$, and the distribution of $N$ is simply given by the binomial distribution $\mathscr{B}(n, 10 \%)$. By way of contrast, if $p^{*}=10 \%, p_{N}=0 \%$ and $p_{C}=100 \%$, the loss probability is also $p=10 \%$ but the risks are highly correlated, since the probability of claiming a loss is 1 in case of a catastrophe (i.e. we have a $p^{*}=10 \%$ chance that everybody claims a loss) and 0 otherwise (i.e. we have a $1-p^{*}=90 \%$ chance of no loss). More generally, given Equation (11), the distribution function of $N$ (and $X$ ) can be defined by the following mixture of two binomial distributions:

$$
\begin{aligned}
F(x) & =\mathbb{P}(N \leq k)=\mathbb{P}(N \leq k \mid \text { No Cat }) \times \mathbb{P}(\text { No Cat })+\mathbb{P}(N \leq k \mid \text { Cat }) \times \mathbb{P}(\text { Cat }), \\
& =\sum_{j=0}^{k}\left(\begin{array}{l}
n \\
j
\end{array}\right)\left[\left(p_{N}\right)^{j}\left(1-p_{N}\right)^{n-j}\left(1-p^{*}\right)+\left(p_{C}\right)^{j}\left(1-p_{C}\right)^{n-j} p^{*}\right]
\end{aligned}
$$


where $k=\lfloor n x\rfloor$. To simplify, we can set:

$$
p_{C}=\frac{1}{1-\delta} p_{N}
$$

which allows us to write $p_{N}$ and $p_{C}$ as functions of $p^{*}, p$ and $\delta$ (using Equations (11) and (14)):

$$
\begin{aligned}
p_{N} & =\frac{(1-\delta) p}{1-\delta+\delta p^{*}} \\
p_{C} & =\frac{p}{1-\delta+\delta p^{*}}
\end{aligned}
$$

The coefficient $\delta \in\left[0, \min \left\{1, \frac{1-p}{1-p^{*}}\right\}\right]$ is crucial in our analysis, and can be seen as a proxy for the within-correlation.

Proposition 7. The coefficient $\delta$ is an increasing monotonic function of the correlation between the individual risks.

Proof. See the Appendix.

Figure 4 provides an illustration of the cumulative distribution function $F$ when $n=500$, $p^{*}=0.1, p=0.3$, and $\delta=0.4$. In this case, the probabilities $p_{N}$ and $p_{C}$ are equal to 0.28 and 0.47 respectively. Using this statistical modeling, we can test our theoretical framework and check the validity of the properties of $F$ as described in Equation (2): (i) in the bottompanel of Figure 4, the individual probability $p$ is also the expectation of $X$; (ii) when the loss probability $p$ rises from 0.3 to 0.5 (see the top panel of Figure 5), the distribution function shifts to the right, with $p_{N}=0.47$ and $p_{C}=0.78$; (iii and v) the probability of an extreme event, for instance $x=0.8$, increases with $p$ and $\delta$ (see the bottom panel of Figures 5 and 6 , respectively); (iv) a rise in $\delta$ from 0.4 to 0.7 implies a fall in $p_{N}$ to 0.24 , and a rise in $p_{C}$ to 0.81 , so that when $\delta$ is high, there is either a small or an extreme event (see Figure 6); and (vi) in Figure 6, a rise in $\delta$ has no effect on $p$. Note that our theoretical analysis concentrated on the right-hand side of the distribution function, where $x$ is greater than $x^{*}=p_{C}$.

Figure 7 illustrates the outcome with an infinite number of agents. With correlated risks (the top panel of Figure 7), the cumulative distribution function $F$ still has two bends, but they are much sharper. Two possible states of nature can be observed depending on whether a natural disaster occurs. The insurance company can set the premium so that $\bar{x}$ is between $p_{N}$ and $p_{C}$. In this case, the company has a $10 \%$ chance of insolvency. The insurance company can also set the premium so that $\bar{x}$ is greater than $p_{C}$, which will guarantee a zero insolvency probability. With uncorrelated risks (the bottom panel of Figure 7), the function $F$ has only one bend, and the Law of Large Numbers holds. The insurer can set the premium so that $\bar{x}$ is greater than $p=0.30$, which will guarantee a zero insolvency probability. 

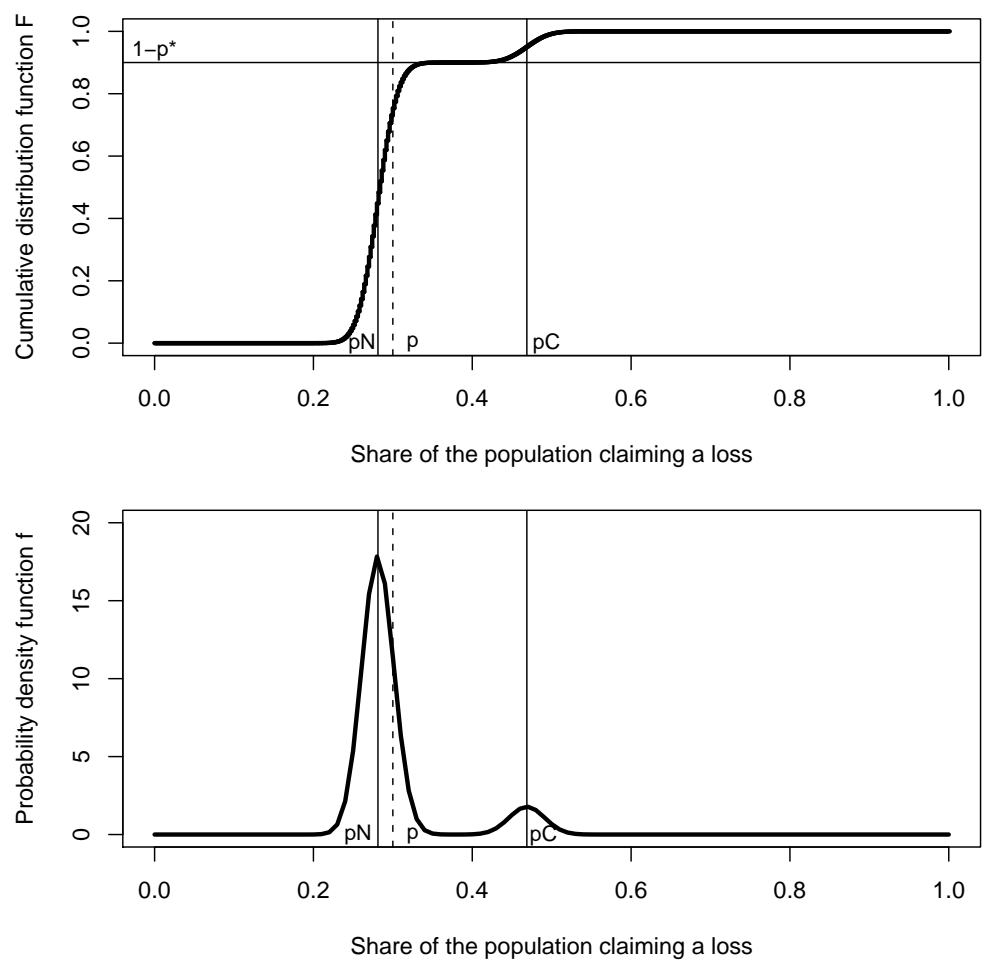

Figure 4. Functions $F$ and $f\left(n=500, p^{*}=0.1, p=0.3, \delta=0.4\right)$
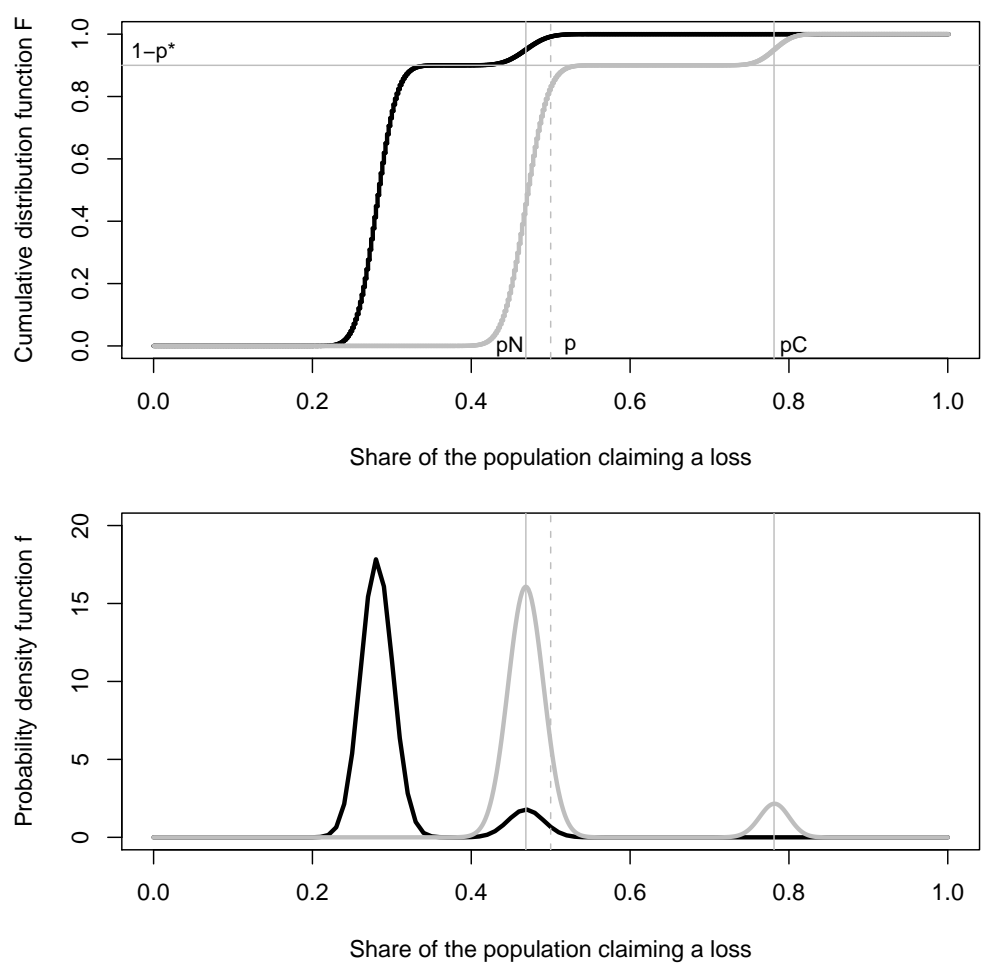

Figure 5. Impact of an increase in $p$ on $F$ and $f(p=0.3$ then 0.5$)$. 

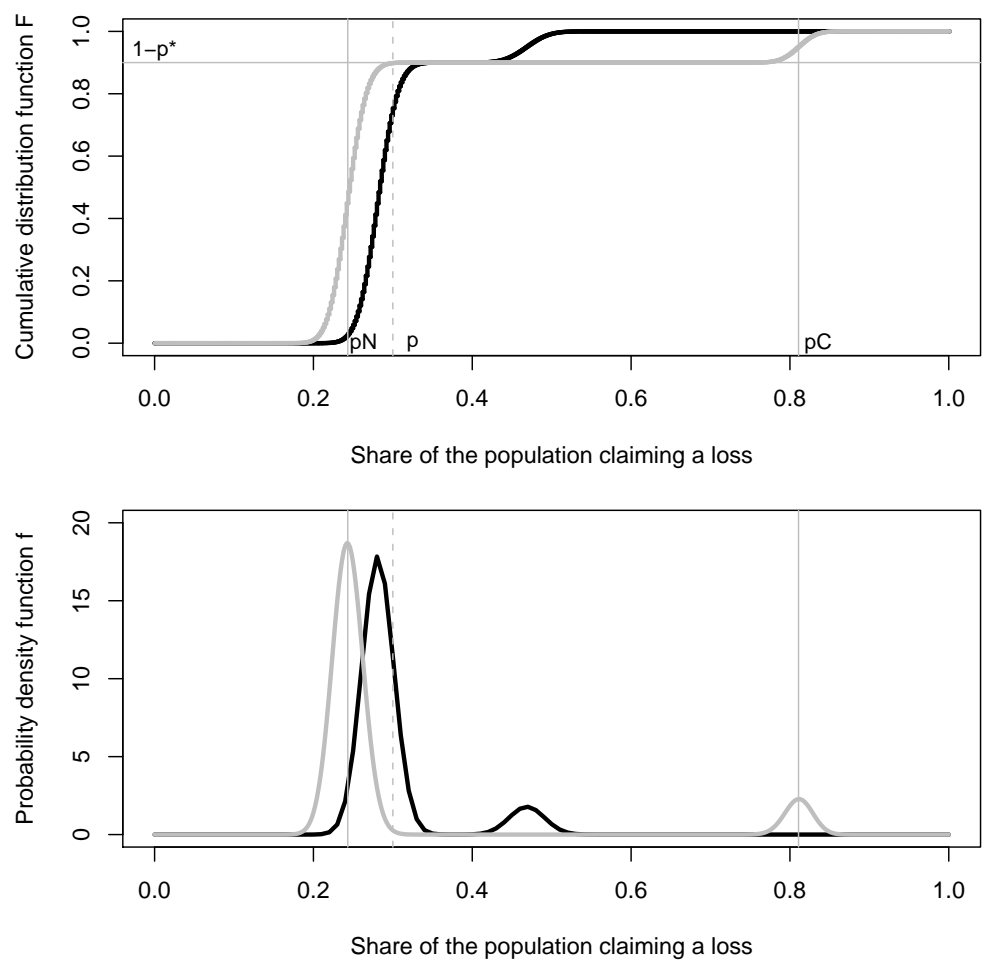

Figure 6. Impact of an increase in $\delta$ on $F$ and $f(\delta=0.4$ then 0.7$)$.
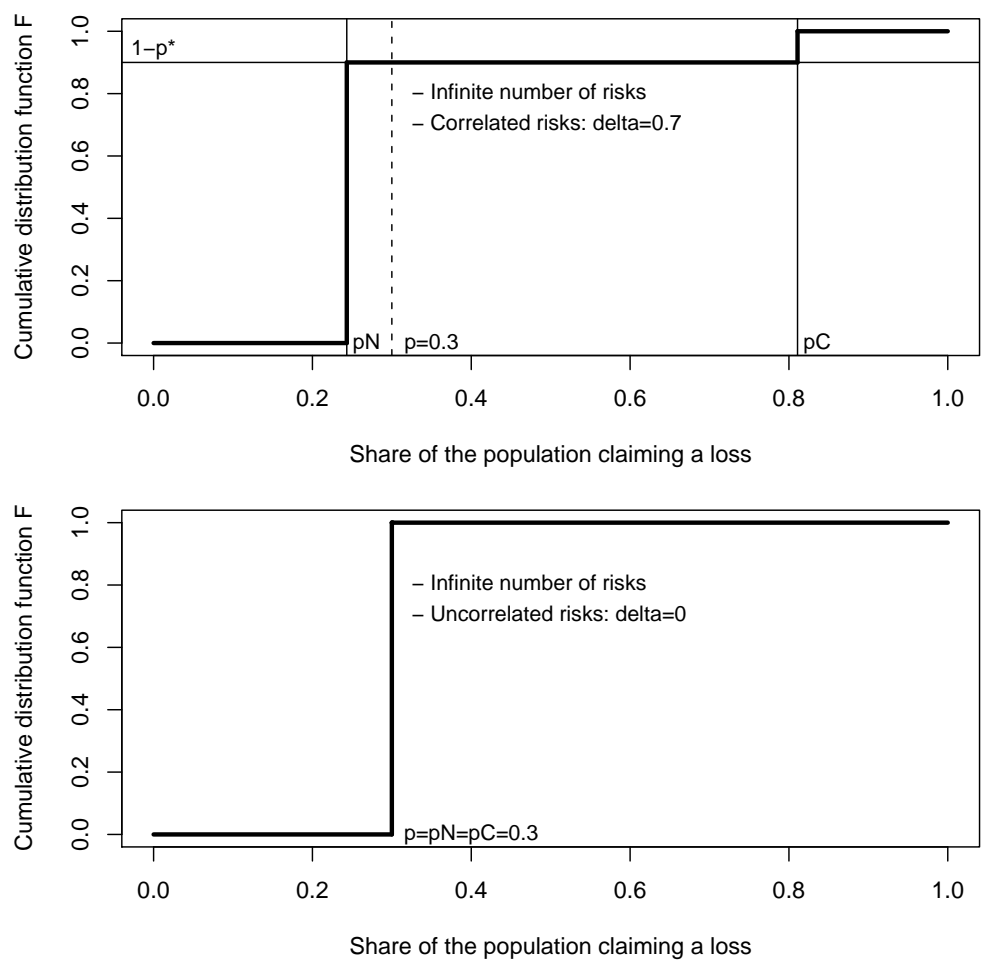

Figure 7. Infinite number of agents: $n=+\infty$ 
Table 4. Catastrophe probabilities in the two-region economy.

\begin{tabular}{lc|c|c|c}
\hline \hline & \multicolumn{2}{c}{ Cat in Region 1 } & \multicolumn{2}{c}{ No Cat in Region 1 } \\
\hline & Cat in Region 2 & No Cat in Region 2 & Cat in Region 2 & No Cat in Region 2 \\
\hline General case & $\theta$ & $p^{*}-\theta$ & $p^{*}-\theta$ & $1-2 p^{*}+\theta$ \\
Perfectly independent & $\left(p^{*}\right)^{2}$ & $p^{*}\left(1-p^{*}\right)$ & $p^{*}\left(1-p^{*}\right)$ & $\left(1-p^{*}\right)\left(1-p^{*}\right)$ \\
Positively dependent & $p^{*}$ & 0 & 0 & $1-p^{*}$ \\
\hline \hline
\end{tabular}

\subsection{Modeling the between-correlations}

Consider two regions with the same probability $p^{*}$ of a catastrophe. The probabilities $p_{C}$ and $p_{N}$ may be different from one region to the other, and will be denoted by $P_{C}^{1}, P_{N}^{1}, P_{C}^{2}, P_{N}^{2}$ for Region 1 and Region 2, respectively. The distribution function $F_{0}$ of natural events over the whole economy can be derived from a mixture of the $F_{1}$ and $F_{2}$ observed in each region. There are four possible cases, depending on whether the regions experience a catastrophe or not. These possible cases are described in Table 4. Let $p_{C C}=\theta$ denote the probability that Regions 1 and 2 are both victims of a catastrophe, $p_{C N}=p^{*}-\theta$ the probability that only Region 1 is hit, $p_{N C}=p^{*}-\theta$ when only Region 2 is hit, and $p_{N N}=1-2 p^{*}+\theta$ the probability that neither Region 1 nor 2 is hit. The probability density function of $X_{0}$ can be defined as:

$$
f_{0}(x)=p_{C C} f_{C C}(x)+p_{C N} f_{C N}(x)+p_{N C} f_{N C}(x)+p_{N N} f_{N N}(x)
$$

with

$$
f_{a b}(x)=\mathscr{B}\left(n_{1}, p_{a}^{1}\right) \star \mathscr{B}\left(n_{2}, p_{b}^{2}\right),
$$

where $a, b \in\{C, N\}$ and $\star$ denotes the convolution operator. Here, $p_{C C}=\theta$ represents the between-correlation.

Figure 8 shows the case where the risks between the regions are perfectly independent, i.e. $\theta=\left(p^{*}\right)^{2}$. The black lines represent the cumulative distribution function $F_{1}$ (in the top panel) and the density $f_{1}$ in Region 1 (bottom panel) when $p=0.3, n_{1}=500$ and $\delta_{1}=0.5$. The grey curves depict $F_{0}$ and $f_{0}$ when Region 1 is pooled with an identical region. In the vicinity of $x^{*}=p_{C}$, we can see that $F_{0}$ is above $F_{1}$, i.e. pooling Region 1 with another region reduces the probability of an extreme event. By way of contrast, when the risks are positively correlated, i.e. when $\theta=p^{*}, F_{0}$ is below $F_{1}$ in the vicinity of $p_{C}$ (see Figure 9). In this case, pooling Region 1 with another region increases the probability of an extreme event. This corresponds to properties (v) and (vi) of the two-region model (see Equation (10)).

In Figure 10, the risks between the regions are independent, i.e. $\theta=\left(p^{*}\right)^{2}$, but Region 1 has a lower within-correlation than Region $2\left(\delta_{1}=0.5\right.$ and $\left.\delta_{2}=0.7\right)$. We can see that $F_{0}$ is below $F_{1}$ around $p_{C}$, so that pooling Region 1 with a riskier area will be detrimental to Region 1. On the other hand, pooling Region 1 with a safer area will be beneficial to Region 1 (see Figure 11 where $\delta_{1}=0.5$ and $\delta_{2}=0.3$ ). This corresponds to properties (v) and (vi) of the 

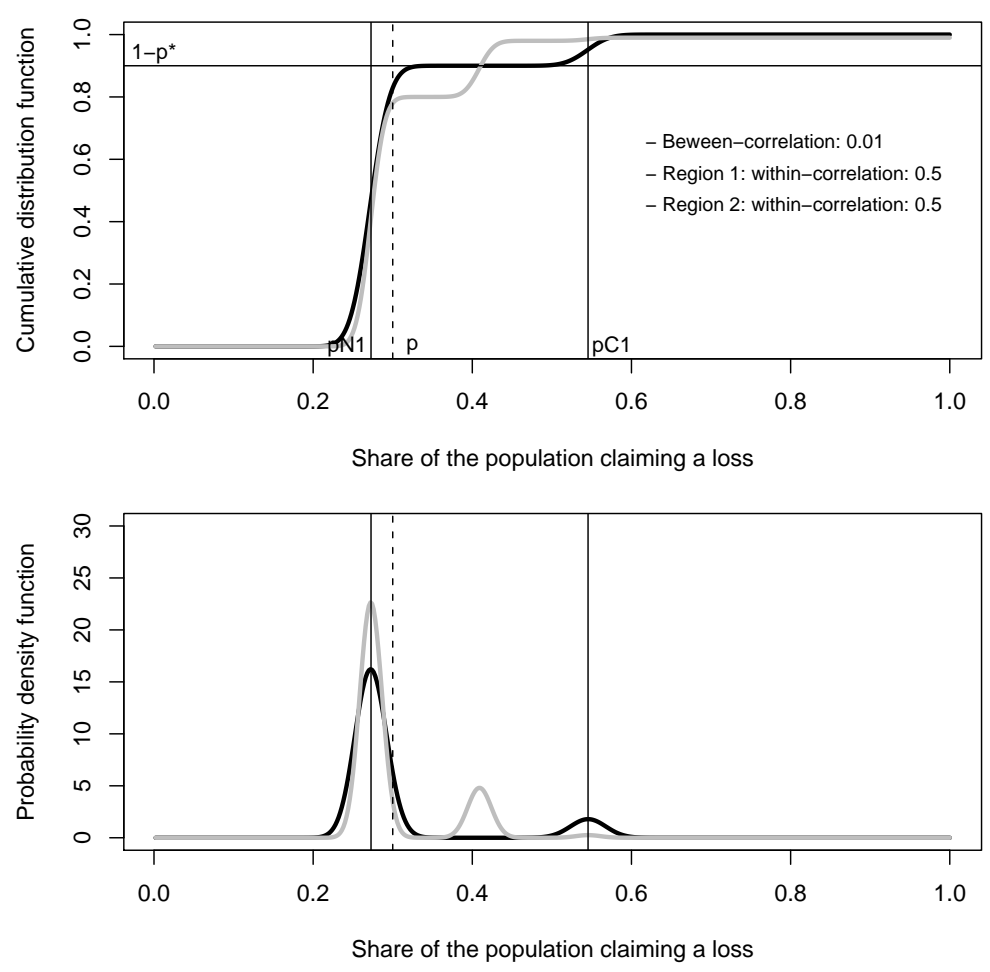

Figure 8. $F_{1}$ and $F_{0}$ when the risks are perfectly independent.

two-region model (see Equation (10)).

\subsection{Application to the one-region model}

This subsection investigates the one-region model by simulations using the mixture model of Subsection 5.1. Although we will not carry out the analysis here, the simulations can easily be extended to the two-region model. For graphical convenience, the probability of a catastrophe $p^{*}$ will be fixed at 0.05 , while the loss will be set at $l=1, n$ to 1000 , and the utility function to $U(Y)=100\left(1-e^{-2 Y}\right.$ ). This $U$ function is concave (policyholders are risk-averse) and belongs to the CARA class of utility functions, with a constant Arrow-Pratt measure of Absolute Risk Aversion.

Figure 12 shows expected utility $V$ as a function of the premium $\alpha$ for $c=0.05, \delta=0.9$ and $p=0.1$. The grey line represents expected utility without government intervention, and the thin black line the unlimited-guarantee scenario. The thick black line shows expected utility when there is a zero probability of insolvency, i.e. $U(-\alpha)$. Consistent with our expectations, the thick black line is above the other curves and expected utility is higher with unlimited guarantee than without.

The two dots on the right-hand side correspond to the willingness to pay $\left(\alpha^{*}\right)$. The values are obtained for the highest possible premia such that inhabitants are indifferent between $V$ and $p U(-l)$. These dots characterize the market equilibrium when the market is not perfectly competitive. Expected utility is equal to $p U(-l)=-63.9$ in both cases, with 

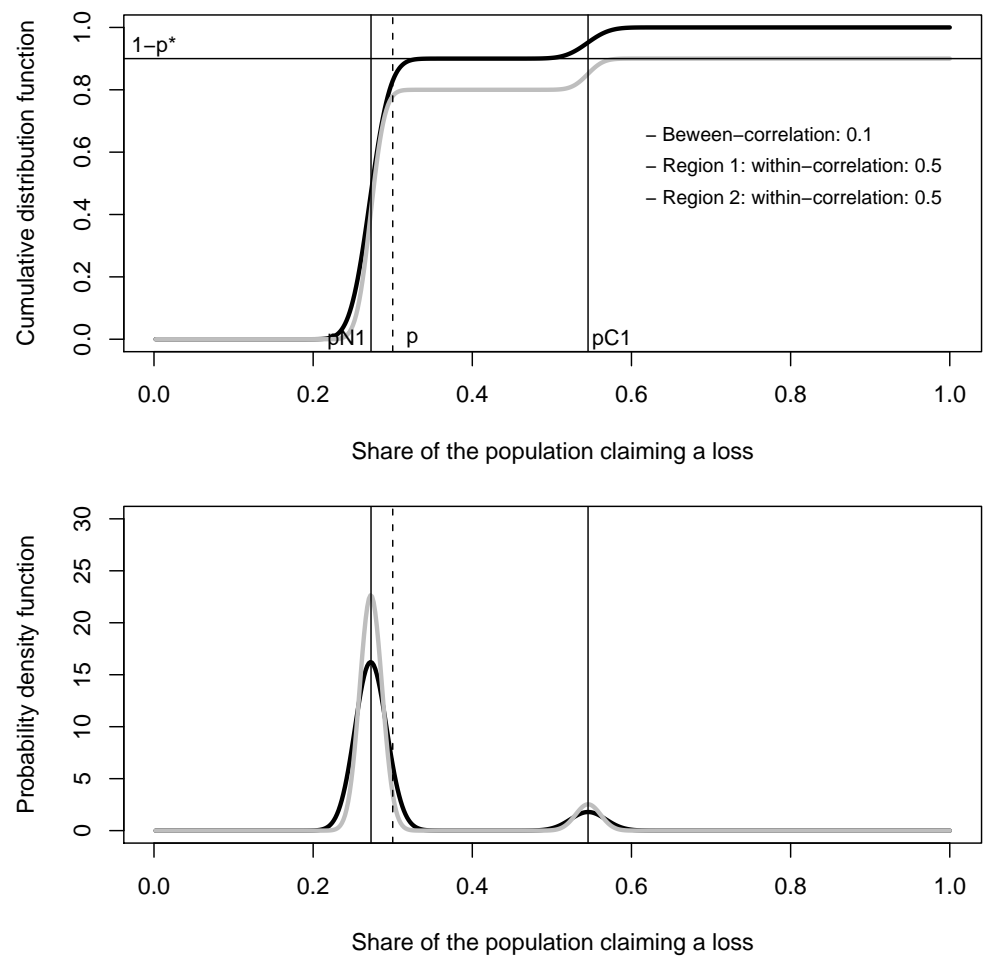

Figure 9. $F_{1}$ and $F_{0}$ when the risks are positively dependent.
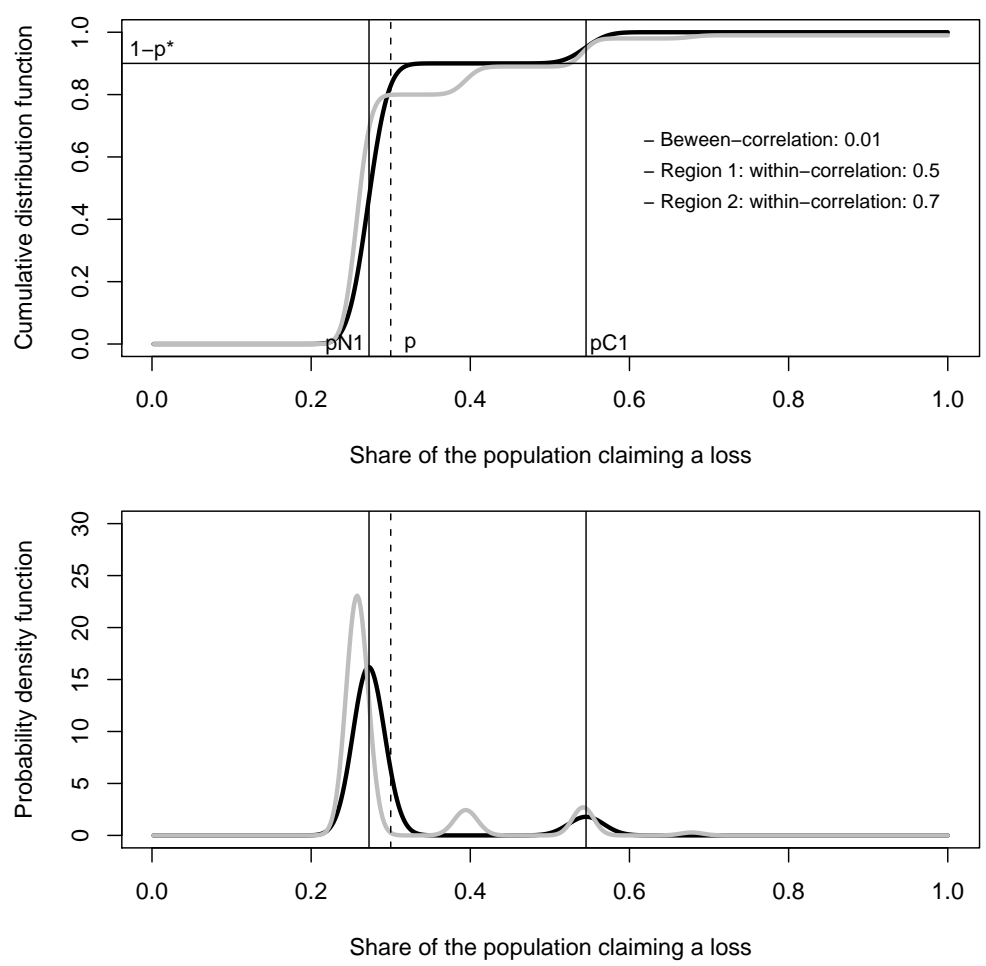

Figure 10. $F_{1}$ and $F_{0}$ when Region 1 has a lower within-correlation. 

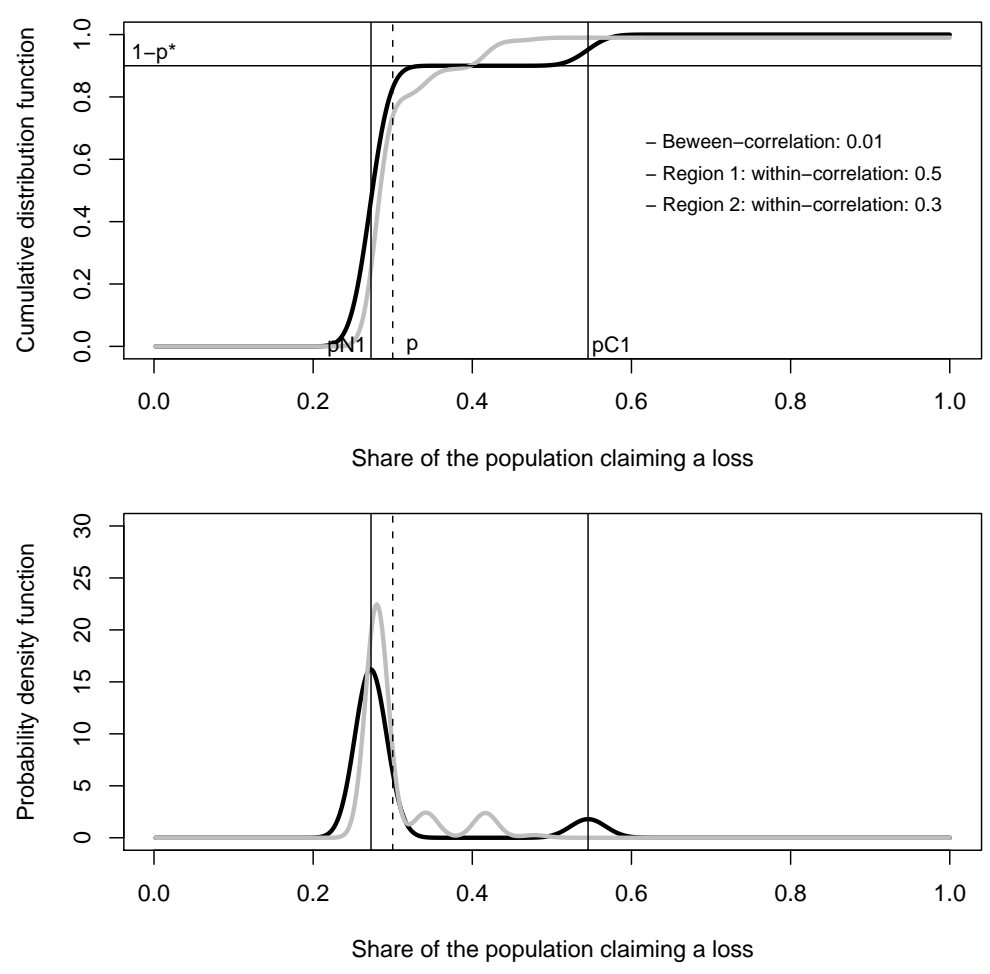

Figure 11. $F_{1}$ and $F_{0}$ when Region 1 has a higher within-correlation.

$\alpha^{*}=0.206$ without government intervention and 0.216 with intervention. The two dots on the left-hand side correspond to the lowest possible premia such that the expected profit of the insurance company is non-negative. This situation could come about with a competitive market or a regulated monopoly, for example.

As demonstrated in Proposition 2, under limited-liability insurance, expected utility initially rises with the premium and then falls (see Figure 12, for instance). This result does not hold with government intervention. This can easily be explained. Recall that insolvency occurs when $x>\left(\bar{x}=\frac{\alpha+c}{l}\right)$. If $\alpha$ is small, the probability of insolvency is very high (almost 1 ), while the indemnity received by the policyholders is close to $n c / N$, i.e. very small. Without government intervention, a rising premium will generate a greater indemnity and reduce the probability of insolvency. As the probability of insolvency becomes insignificant, expected utility will as usual fall with the premium. By way of contrast, with government intervention, full coverage will always be guaranteed. An increase in the premium will then only serve the interests of the insurance company.

Figures 13 and 14 provide an illustration of Propositions 2 and 3. In Figure 13, a fall in the correlation from 0.9 to 0.8 has a positive effect on expected utility and willingness to pay; similar results are found in Figure 14 for a rise in capital per head from $c=0.05$ to 0.08 . In both figures, the lowest possible premia such that expected profit is still positive (the two dots on the left) rise as shareholders will be more exposed to industry failure (Proposition 1). 


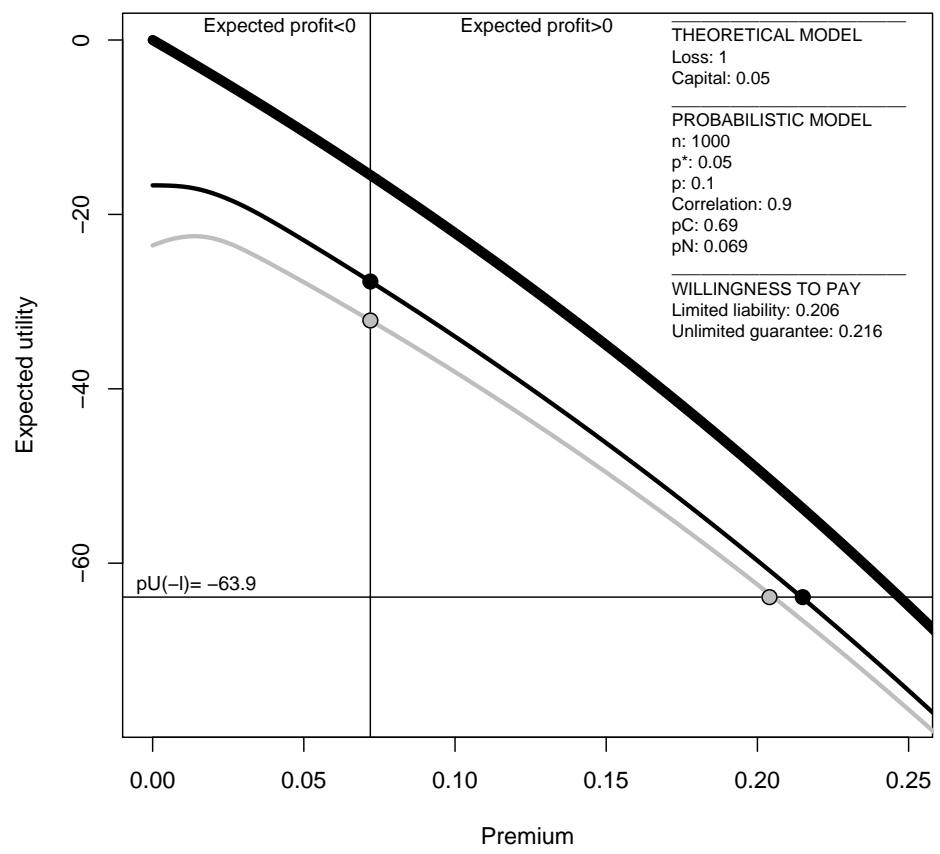

Figure 12. Comparison of scenarios.

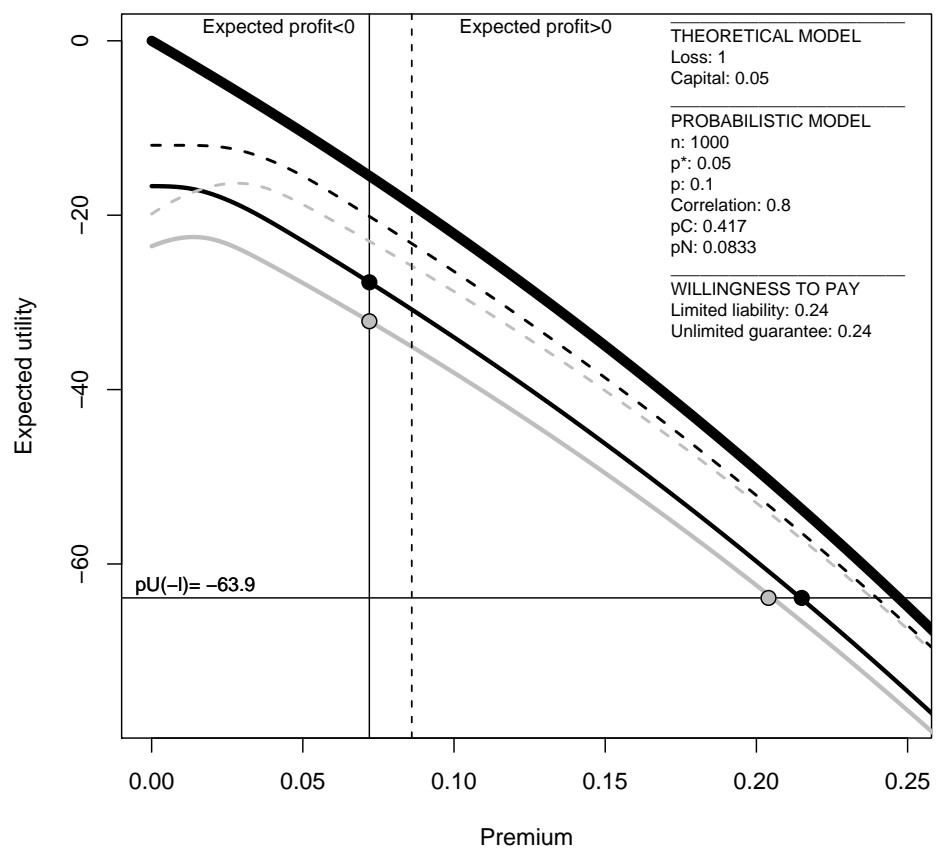

Figure 13. Effect of a fall in $\delta$ from 0.9 (unbroken line) to 0.8 (dotted line). 


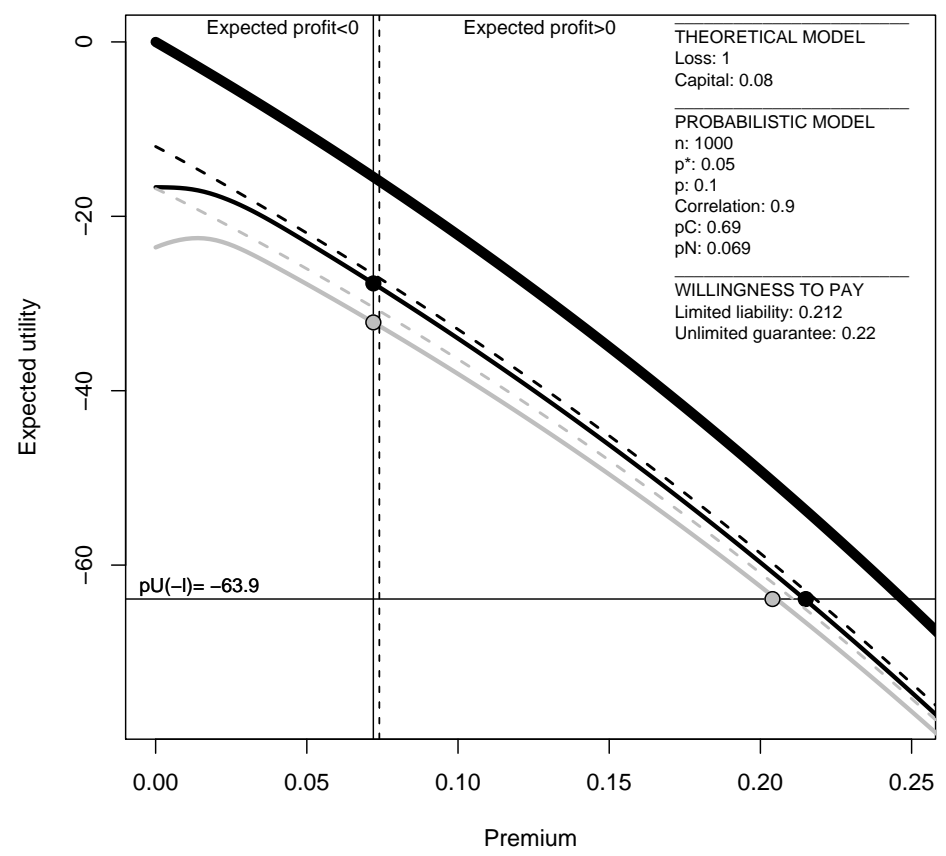

Figure 14. Effect of a rise in c from 0.05 (unbroken line) to 0.08 (dotted line).

Table 5. A simple illustration of the problem. ${ }^{a}$

\begin{tabular}{l|c|c|c|c|c}
\hline \hline & Region 1 & Region 2 & Region 3 & Regions 1+2 & Regions 1+3 \\
\hline 1. Loss per inhabitant in Year 1 & 5 & 65 & 35 & 35 & 20 \\
2. Loss per inhabitant in Year 2 & 95 & 35 & 65 & 65 & 80 \\
\hline 3. Average of annual losses & 50 & 50 & 50 & 50 & 50 \\
4. Variance of annual losses & 2025 & 225 & 225 & 225 & 900 \\
5. Pearson correlation coefficient & & & & -1 & +1 \\
\hline \hline
\end{tabular}

${ }^{a}$ The number of inhabitants is the same in each region. 


\section{Policy implications}

The results we have obtained, both from the theoretical model under a set of assumptions and the ad hoc statistical model, yield a better understanding of insurance markets with natural catastrophes. The three main elements behind the occurrence of natural events were the probability $(p)$ that each individual claim a loss, the within-correlation $(\delta)$ between the individual risks, and the between-correlation $(\theta)$, i.e. how risks are correlated between two regions.

In practice, the model parameters can easily be approximated. For pedagogical reasons, instead of focusing on a real-world case study, we prefer to consider a simpler illustration with only two years of catastrophic losses (see Table 5). This approach will allow us to illustrate several key concepts. In Table 5, the average of the losses (Row 3) is an approximation of the level of risk, and as such reflects $p$ in our model. While this level of risk is the same in each region, the time profile of the losses (Rows 1 and 2) is different, thus affecting the probability that the insurance industry become insolvent. The variance over time (Row 4) can actually be considered as a proxy for $\delta$ : this variance is high in Region 1 as both a small and an extreme event occur. By way of contrast, the losses per capita in Regions 2 and 3 converge toward the average, so that there is only a low within-correlation. The between-correlation $\theta$ can be approximated by the Pearson correlation coefficient (Row 5): the natural risks in Regions 1 are more correlated with those in Region 3 than they are with those in Region 2.

The within-correlation $\delta$ plays an important role in our theoretical framework. For instance, in Table 5 an insurer will prefer to insure Regions 2 and 3 because these regions do not face extreme events. Similarly, the willingness to pay for insurance will be higher in these regions, as the insolvency probability is lower. In other words, insurance coverage is more likely to be provided in Regions 2 and 3 than it is in Region 1. How can we solve the problem of Region 1 in a Pareto-efficient manner? The present research suggests a number of solutions within a unified microeconomic framework.

\subsection{The role of capital resources}

Policymakers have often chosen to intervene in the first place via capital requirements. In our model, the willingness to pay for insurance rises with the company's capital. This presumes that potential clients are able to make rational decisions about low-probability, highconsequence events, i.e. that they are not rationally bounded and concerned with solvency.

A number of US analyses have found that demand responds to the insurer's financialstrength rating (see for instance Sommer, 1996; Cummins and Danzon, 1997; Epermanis and Harrington, 2006). As such, as in our model, greater capital requirements would benefit potential buyers, and allow insurers to propose higher ratings. However, greater capital will also increase the exposure of shareholders to industry failure, thus putting insurance companies in a more uncomfortable position (see Subsection 3.3).

Capital-requirement regulation are not necessarily easy to implement in practice. The decision to increase capital requirements actually depends on the sensitivity of demand to insurers' capital resources. Another possibility would be to reduce the cost of access to capital itself, which will be beneficial on both the demand and supply sides. For instance, some 
authors have suggested the use of capital-market instruments such as CAT bonds or CAT options to help insurance companies access capital in financial markets. Another suggestion has been the creation of tax-deferred catastrophe reserves (Kousky, 2011).

\subsection{A regulated premium}

When faced with natural disasters, private insurers ask for high premia for many reasons. For instance, higher premia protect businesses from financial ruin; the pre-funding of disasters is better than post-funding; and when assessing the risk of a disaster is difficult, it is only rational for the industry to charge high premia. Simply put, premia for catastrophic risks should be higher than for non-catastrophic risks. We have shown that this assertion is true only from the supply-side point of view. A higher premium will reduce the probability of insolvency and lead to higher expected profits. However, from the demand-side, the willingness to pay for catastrophe coverage falls with $\delta$, as correlated risks imply a higher default risk (see Subsection 3.2). For a same level of risk ( $p$ ), catastrophe coverage that is sold at a price higher than that of non-catastrophe coverage should be less attractive to potential buyers.

This problem is also discussed in Kousky and Cooke (2012). They argue that insurers who insure correlated risks need to charge a price that is many times the expected loss in order to satisfy their solvency constraint. On the contrary, homeowners, who face both a budget constraint and the constraint that their utility with insurance exceeds that without, may find the required loadings too high for insurance purchase to be optimal.

On top of those theoretical implications, the potential influence of politics on pricing should be borne in mind. As an example, in the US, "States with a high-level of catastrophe risk, such as Florida and California, have faced strong political pressure to enforce extraordinary measures to constrain the price of catastrophe insurance" (Klein, 1998).

Given these controversial effects, it is difficult to imagine that a regulated price will be of any use, unless the goal is to solve market inefficiencies resulting from imperfect competition and imperfect information (see, e.g., Epple and Schäfer, 1996; Jaffee and Russell, 1997). For instance, we have shown in Subsection 3.3 that a non perfectly-competitive market may lead the industry to propose a price equal to policyholders' willingness to pay, thus reducing their benefit from insurance coverage to zero.

\subsection{The importance of risk diversification}

The natural-catastrophe insurance industry may be characterized by economies of scale if the between-correlation $(\theta)$ is sufficiently low (see Subsection 3.3). For instance, we can see from the two last columns of Table 5 that an insurer would benefit from pooling Regions 1 and 2, but not from pooling Regions 1 and 3.

The growth of private reinsurance coverage throughout the world in recent decades has resulted in a much larger and more efficient geographical pooling of risk. In addition, a number of countries have set up guarantee or solvency funds to protect policyholders in the event that an insurer goes bankrupt. These guarantee funds are financed by the insurance companies and work somewhat similarly to a reinsurance pool. However, contributions are not based on insurer risks, which is often criticized. Our two-region model illustrates the 
problem: an insurer in a safer region will accept to pay the same contribution as the others if and only if (1) the risk of default is sufficiently reduced and (2) demand is sufficiently sensitive to insurers' financial strength. If not, the introduction of guarantee funds would hurt less-risky firms. Risk-based contributions also have the advantage of reducing the risk of moral hazard by preventing insurers from adopting high-risk strategies (Cummins, 1988).

Despite the existence of reinsurance coverage and guarantee funds, many insurers still refuse to provide coverage for overly-risky areas. This was the case in the US where insurers did not provide flood-insurance coverage, as flood hazards were typically confined to a few areas. Other examples can be found in Germany, where some people living in BadenWürttemberg could not find insurance covering them against the periodically-recurring floods (Epple and Schäfer, 1996). All these problems were solved by the creation of government programs.

\subsection{Unlimited guarantee from the government}

Because it spreads the risks more equally among policyholders, government-provided insurance will be more attractive to policyholders. This allows insurers to sell coverage at higher prices, reducing the insolvency probability, lead to higher expected profits, and may guarantee the existence of catastrophe coverage (see Subsections 3.2 and 3.3).

Consider, for instance, $n=100,000$ taxpayers who bought insurance coverage. Suppose that $x=1 \%$ of this population, i.e., $N=1,000$ victims, will claim a loss of $l=\$ 100,000$. The total loss is then $\$ 100$ million. Moreover, assume that the insurance industry is able to pay maximum compensation of $\$ 80$ million. With a limited-liability corporation, each claim will generate large negative externalities: the 1,000 victims will receive a reduced indemnity of $I=\frac{\$ 80 \text { million }}{1,000}=\$ 80,000$ and will thus lose $I-l=\$ 20,000$. Since an agent has a $x=1 \%$ likelihood of being one of the victims, the expected loss is $0.01 \times 20,000+0.99 \times 0=\$ 200$. On the contrary, if the government intervenes as an insurer of last resort, it does not matter whether an agent claims a loss or not as all $n$ taxpayers are supposed to finance the payment default. Everyone will lose $T=\frac{\$ 20 \text { million }}{100,000}=\$ 200$. Under this unlimited-guarantee scenario, each claim represents a negative pecuniary externality, not only for the victims, but also for the rest of the population.

Comparing the two scenarios leads us to conclude that the limited-liability scenario is a mean-preserving spread of the unlimited-guarantee case. If individuals are risk-averse, they will prefer the unlimited-guarantee scenario. Of course, in practice, people do not know $x$ with certainty and face a larger number of possible states of nature. However, this result was generalized in Section 3 using the Independence Axiom of von Neumann-Morgenstern Expected Utility Theory.

To sum up, the advantage of a government program over the limited-liability case comes from the possibility of ex-post budgeting, leading to less-risky lotteries. This comes about as the private sector may face some difficulty in imposing participation or obtaining access to credit once bankrupted. In practice, a government program can be financed by higher taxes or borrowing. In any case, it should be stressed that the Barro-Ricardo equivalence theorem may apply in our model, i.e., the timing of the loan should not affect the present value of the 
budget and, as such, our results would not change were we to include deficits.

\subsection{A government program should be appropriately priced}

While an unlimited guarantee may be an appropriate way of spreading risks, it does raise other questions. To put our model in context it is useful to consider the US National Flood Insurance Program (NFIP). One frequently-asked question about NFIP is: "Will policyholders in non-coastal states pay more for flood insurance to support losses along the coast?". The answer is that premia are based on risk, not location. Two housing units with the same risk ( $p$ in our model) but located in areas with different potential damage (related to $\delta$ in our model) - for example, one in a shallow floodplain and the other in a steep and narrow mountain valley - will be charged the same rate (GAO, 2008). According to the two-region model developed in Section 4, this pricing policy may be inefficient. For instance, in Table 5, a government program that brings together Regions 1 and 3 cannot be politically viable in the long run. The inhabitants of Region 3 would not understand why they should pay the same price as those in Region 1. To be politically viable, the government program should propose a lower fee to Region 3. In Klein (1998), additional examples are given in the context of multi-State insurance which can also be related to the model's conclusions.

The two-region model provides a useful normative tool for regulation. Given the pecuniary externalities one region may impose on another, the insurance premia under a government program should be based not only on the level of risk $(p)$, i.e. on expected losses (a basic actuarial principle), but also on how the risks are correlated between and within regions $(\delta$ and $\theta$ ), i.e. on the variance of the losses (which has never been applied, to our knowledge). In particular, government officials must be prepared to announce rates lower than usual in order to attract safer regions.

Another important motivation for government intervention is the ability of the government to force take-up across risk levels and then broaden the risk base across which insurance is provided. In the two-region model, policyholders benefit from pooling with independent risks from another region. This is all the more true if the covered damages are different, e.g., earthquake vs. flood. This considerably reduces the between-correlation and increases the willingness to pay for insurance coverage.

\section{Concluding remarks}

This paper has highlighted some key mechanisms connecting the premium rate, capital, risk correlation, and the decision to provide or buy insurance. Given our results, it is not surprising that so many industrialized nations have intervened in catastrophe-insurance markets, even though the implemented programs have sometimes suffered from severe financial difficulties. The probability of failure of a government program should be lower than that in a purelyprivate market: risk-averse policyholders will accept to pay higher rates for unlimitedguarantee insurance, thus reducing the probability of insolvency. To limit protests from the less-correlated areas, these rates should be calculated based on how risks are correlated between and within the jurisdictions involved. 
We suspect that the current research could also apply in other situations. For example, insurance against terrorism, the provision of fire protection, health programs and unemployment insurance, could be analysed in this light. Moreover, while the present analysis has compared public and private programs from a normative point of view, it has not, however, addressed all the political realities of government-insurance programs. We could go further here by introducing self-interested government officials into the model. For example, the government tax in our model is not risk-based - that is, it is paid equally by all policyholders. There are thus distributional issues. As shown above, some of these can be addressed by appropriate risk-based premia. However, the approach may lead to PrincipalAgent problems: first, regional governments could use their informational advantage and lie to the central government about their risks. Second, they may have an incentive to underprice their coverage, in order to gain from the redistributive scheme at the expense of the other regions.

Last, there are a number of related problems which were not examined here, such as the influence of risk mitigation, and the role of bounded rationality in insurance decisions. By assuming that the government will have in place appropriate land-use and building regulations, we also ruled out the risk of moral hazard. There could in addition be substantial transaction costs for a government program that adopted fine-grained risk-based pricing which is updated over time. These and other questions provide a considerable source of inspiration for future research. 


\section{A. Appendix}

\section{A.1. Proof of Proposition 1}

Recall that insurance-company profit is:

$$
\Pi(\alpha, p, \delta, c)=\int_{0}^{\bar{x}}[n \alpha-x n l] f(x) d x-[1-F(\bar{x})] c n \quad \text { with } \quad \bar{x}=[\alpha+c] / l .
$$

From the Leibniz rule, the partial derivative with respect to $c$ is:

$$
\frac{\partial \Pi}{\partial c}=\frac{\partial \bar{x}(c)}{\partial c}[n \alpha-\bar{x}(c) n l] f(\bar{x}(c))-[1-F(\bar{x}(c))] n+\frac{\partial F(\bar{x}(c))}{\partial c} c n .
$$

Thus,

$$
\frac{\partial \Pi}{\partial c}=\frac{1}{l}[n \alpha-\bar{x} n l] f(\bar{x})-[1-F(\bar{x})] n+\frac{1}{l} f(\bar{x}) c n=-[1-F(\bar{x})] n<0 .
$$

From the Leibniz rule, the partial derivative with respect to $\alpha$ is:

$$
\frac{\partial \Pi}{\partial \alpha}=\frac{\partial \bar{x}(\alpha)}{\partial \alpha}[n \alpha-\bar{x}(\alpha) n l] f(\bar{x}(\alpha))+\int_{0}^{\bar{x}(\alpha)} n f(x) d x+\frac{\partial F(\bar{x}(\alpha))}{\partial \alpha} c n .
$$

Thus,

$$
\frac{\partial \Pi}{\partial \alpha}=\frac{1}{l}[n \alpha-\bar{x} n l] f(\bar{x})+n F(\bar{x})+\frac{1}{l} f(\bar{x}) c n=n F(\bar{x})>0 .
$$

\section{A.2. Proof of Proposition 2}

The scenario with limited liability. Expected utility $V$ can be rewritten as:

$$
V(\alpha, p, \delta, c)=U(-\alpha)-\int_{\bar{x}}^{1}[U(-\alpha)-U(-\alpha-l+I(x))] x f(x) d x \text { with } I(x)=\frac{c+\alpha}{x} .
$$

From the Leibniz rule, the partial derivative with respect to $\alpha$ is:

$$
\frac{\partial V}{\partial \alpha}=-U^{\prime}(-\alpha)+\frac{1}{l}[U(-\alpha)-U(-\alpha-l+I(\bar{x}))] \bar{x} f(\bar{x})-\int_{\bar{x}}^{1}\left[-U^{\prime}(-\alpha)+\left(1-\frac{1}{x}\right) U^{\prime}(-\alpha-l+I(x))\right] x f(x) d x .
$$

As $\bar{x}=[\alpha+c] / l$ and $I(\bar{x})=\frac{c+\alpha}{x}=l$, the middle term can be set to 0 , which yields:

$$
\frac{\partial V}{\partial \alpha}=-U^{\prime}(-\alpha)-\int_{\bar{x}}^{1}\left[-U^{\prime}(-\alpha)+\left(1-\frac{1}{x}\right) U^{\prime}(-\alpha-l+I(x))\right] x f(x) d x .
$$

Consider now a first-order development of $U^{\prime}$, for all $x>\bar{x}$,

$$
U^{\prime}(-\alpha-l+I(x)) \approx U^{\prime}(-\alpha)+[-l+I(x)] U^{\prime \prime}(-\alpha) .
$$

Then

$$
(1-x) U^{\prime}(-\alpha-l+I(x))+x U^{\prime}(\alpha) \approx U^{\prime}(\alpha)+(1-x)[-l+I(x)] U^{\prime \prime}(-\alpha) .
$$

Since $[-l+I(x)]=[I(x)-I(\bar{x})]$, we have

$$
\frac{\partial V}{\partial \alpha} \approx-U^{\prime}(-\alpha)+\int_{\bar{x}}^{1} U^{\prime}(\alpha)+\left[(1-x)[I(x)-I(\bar{x})] U^{\prime \prime}(-\alpha)\right] f(x) d x
$$


with

$$
-U^{\prime}(-\alpha)+\int_{\bar{x}}^{1} U^{\prime}(\alpha) f(x) d x=-U^{\prime}(\alpha) \int_{0}^{\bar{x}} f(x) d x=-U^{\prime}(\alpha) \times \mathbb{P}(X \leq \bar{x}),
$$

where $\mathbb{P}(X>\bar{x})$ is the probability of insolvency. Moreover,

$$
U^{\prime \prime}(-\alpha) \times \int_{\bar{x}}^{1}(1-x)[I(x)-I(\bar{x})] f(x) d x=-U^{\prime \prime}(-\alpha) \times H(\bar{x}),
$$

where $H(\bar{x})=\int_{\bar{x}}^{1}(1-x)[I(\bar{x})-I(x)] f(x) d x$ is a positive function which falls with $\bar{x}$. Hence $\frac{\partial V}{\partial \alpha} \leq 0$ implies:

$$
-U^{\prime \prime}(-\alpha) \times H(\bar{x}) \leq U^{\prime}(\alpha) \times \mathbb{P}(X>\bar{x}) \Leftrightarrow \frac{\mathbb{P}(X \leq \bar{x})}{H(\bar{x})} \geq-\frac{U^{\prime \prime}(-\alpha)}{U^{\prime}(\alpha)},
$$

where $\frac{\mathbb{P}(X \leq \bar{x})}{H(\bar{x})}$ is a positive increasing function in $\bar{x}$ and $-\frac{U^{\prime \prime}(-\alpha)}{U^{\prime}(\alpha)}$ stands for the Arrow-Pratt measure of relative risk-aversion. If $U$ is convex, this measure is negative, which implies that $\partial V / \partial \alpha$ is always negative. When $U$ is concave, an inflexion point can exist: (1) if $\bar{x}$ is large (close to 1), then $\partial V / \partial \alpha$ is necessarily negative; (2) if $\bar{x}$ is small, then $\partial V / \partial \alpha$ can be positive.

From the Leibniz rule, the partial derivative with respect to $c$ is:

$$
\frac{\partial V}{\partial c}=\frac{1}{l}[U(-\alpha)-U(-\alpha-l+I(\bar{x}))] f(\bar{x})+\int_{\bar{x}}^{1} U^{\prime}(-\alpha-l+I(\bar{x})) f(x) d x,
$$

i.e., since $I(\bar{x})=l$,

$$
\frac{\partial V}{\partial c}=\int_{\bar{x}}^{1} U^{\prime}(-\alpha-l+I(\bar{x})) f(x) d x>0 .
$$

The partial derivative with respect to $p$ is:

$$
\frac{\partial V}{\partial p}=-\int_{\bar{x}}^{1}[U(-\alpha)-U(-\alpha-l+I(x))] x \frac{\partial f(x)}{\partial p} d x .
$$

which is negative since $\frac{\partial f(x)}{\partial p}>0$ for all $\bar{x}>x^{*}$. Similarly, the partial derivative with respect to $\delta$ is:

$$
\frac{\partial V}{\partial \delta}=-\int_{\bar{x}}^{1}[U(-\alpha)-U(-\alpha-l+I(x))] x \frac{\partial f(x)}{\partial \delta} d x,
$$

which is negative since $\frac{\partial f(x)}{\partial \delta}>0$ for all $\bar{x}>x^{*}$.

The scenario with unlimited guarantee. Expected utility $V$ can be written as:

$$
V(\alpha, p, \delta, c)=\int_{0}^{\bar{x}} U(-\alpha) f(x) d x+\int_{\bar{x}}^{1} U(-\alpha-T(x)) f(x) d x \text { with } T(x)=x l-\alpha-c .
$$

From the Leibniz rule, the partial derivative with respect to $\alpha$ is:

$$
\frac{\partial V}{\partial \alpha}=\frac{1}{l} U(-\alpha) f(\bar{x})-F(\bar{x}) U^{\prime}(-\alpha)-\frac{1}{l} U(c-\bar{x} l) f(\bar{x})=-F(\bar{x}) U^{\prime}(-\alpha)<0 .
$$

Expected utility $V$ can also be rewritten as:

$$
V(\alpha, p, \delta, c)=U(-\alpha)-\int_{\bar{x}}^{1}[U(-\alpha)-U(-\alpha-T(x))] f(x) d x \text { with } T(x)=x l-\alpha-c .
$$


From the Leibniz rule, the partial derivative with respect to $c$ is:

$$
\frac{\partial V}{\partial c}=\frac{1}{l}[U(-\alpha)-U(-\alpha-T(\bar{x}))] f(\bar{x}) d x+\int_{\bar{x}}^{1} U^{\prime}(-\alpha-T(x)) f(x) d x,
$$

i.e., since $T(\bar{x})=0$,

$$
\frac{\partial V}{\partial c}=\int_{\bar{x}}^{1} U^{\prime}(-\alpha-T(x)) f(x) d x>0 .
$$

The partial derivative with respect to $p$ is:

$$
\frac{\partial V}{\partial p}=-\int_{\bar{x}}^{1}[U(-\alpha)-U(-\alpha-T(x))] \frac{\partial f(x)}{\partial p} d x,
$$

which is negative since $\frac{\partial f(x)}{\partial p}>0$ for all $\bar{x}>x^{*}$. The partial derivative with respect to $\delta$ is:

$$
\frac{\partial V}{\partial \delta}=-\int_{\bar{x}}^{1}[U(-\alpha)-U(-\alpha-T(x))] \frac{\partial f(x)}{\partial \delta} d x,
$$

which is negative since $\frac{\partial f(x)}{\partial \delta}>0$ for all $\bar{x}>x^{*}$.

\section{A.3. Proof of Proposition 3}

Let $V_{1}=V_{1}\left(\delta_{1}, \alpha\right)$ and $V_{2}=V_{2}\left(\delta_{2}, \alpha\right)$, with $\delta_{1} \leq \delta_{2}$. Let $V_{1}^{-1}$ denote the inverse function of $V_{1}$, with $V_{1}^{-1}=$ $\sup \left\{\alpha \mid V_{1}(\alpha) \geq v\right\}$. It is possible to prove that $V_{1}^{-1}$ is decreasing. Indeed, if $v^{\prime} \leq v^{\prime \prime}$ then we have:

$$
\left\{\alpha \mid V_{1}(\alpha) \geq v^{\prime \prime}\right\} \subset\left\{\alpha \mid V_{1}(\alpha) \geq v^{\prime}\right\} \quad \Rightarrow \quad \sup \left\{\alpha \mid V_{1}(\alpha) \geq v^{\prime \prime}\right\} \leq\left\{\alpha \mid V_{1}(\alpha) \geq v^{\prime}\right\} \quad \Rightarrow \quad V_{1}^{-1}\left(v^{\prime \prime}\right) \leq V_{1}^{-1}\left(v^{\prime}\right) .
$$

From Proposition 2 we know that $V_{1}(\alpha) \geq V_{2}(\alpha)$. Since $V_{1}^{-1}$ is a decreasing function, this is equivalent to:

$$
V_{1}^{-1}\left(V_{1}(\alpha)\right) \leq V_{1}^{-1}\left(V_{2}(\alpha)\right) \quad \Leftrightarrow \quad \alpha \leq V_{1}^{-1}\left(V_{2}(\alpha)\right) .
$$

The willingness to pay is the premium such that people choose to buy insurance, i.e., $V_{1}\left(\alpha_{1}^{*}\right)=p U(-l)$ and $V_{2}\left(\alpha_{2}^{*}\right)=p U(-l)$. Consequently, for $\alpha=\alpha_{2}^{*}$, we have:

$$
\alpha_{2}^{*} \leq V_{1}^{-1}\left(V_{2}\left(\alpha_{2}^{*}\right)\right) \Leftrightarrow \alpha_{2}^{*} \leq V_{1}^{-1}(p U(-l)) \quad \Leftrightarrow \quad \alpha_{2}^{*} \leq \alpha_{1}^{*},
$$

which implies that $\frac{\partial \alpha^{*}}{\partial \delta} \leq 0$. Similarly, since $\frac{\partial V}{\partial c} \geq 0$, we can prove that $\frac{\partial \alpha^{*}}{\partial c} \geq 0$.

\section{A.4. Proof of Proposition 4}

Denote by $\alpha_{l i m}^{*}$ and $\alpha_{u n l i m}^{*}$ the willingness to pay under limited liability and unlimited guarantee, respectively. Let $V_{\text {lim }}$ and $V_{\text {unlim }}$ denote the expected utilities. Since $V_{\text {unlim }}$ is continuous and decreasing, there necessarily exists a decreasing inverse function $V_{\text {unlim }}^{-1}$. The result that $V_{\text {unlim }}$ is greater than $V_{\text {lim }}$ for any value of $\alpha$ implies:

$$
\forall \alpha, \quad V_{\text {unlim }}(\alpha) \geq V_{\text {lim }}(\alpha) \Leftrightarrow V_{\text {unlim }}^{-1}\left(V_{\text {unlim }}(\alpha)\right) \leq V_{\text {unlim }}^{-1}\left(V_{\text {lim }}(\alpha)\right) \Leftrightarrow \alpha \leq V_{\text {unlim }}^{-1}\left(V_{\text {lim }}(\alpha)\right) .
$$

The willingness to pay is the premium such that individuals choose to buy insurance, i.e. $V_{u n l i m}\left(\alpha_{u l i m}^{*}\right)=p u(-l)$ and $V_{\text {lim }}\left(\alpha_{\text {unlim }}^{*}\right)=p u(-l)$. Consequently, for $\alpha=\alpha_{\text {lim }}^{*}$, we have:

$$
\alpha_{\text {lim }}^{*} \leq V_{\text {unlim }}^{-1}\left(V_{\text {lim }}\left(\alpha_{\text {lim }}^{*}\right)\right) \Leftrightarrow \alpha_{\text {lim }}^{*} \leq V_{\text {unlim }}^{-1}(p U(-l)) \quad \Leftrightarrow \quad \alpha_{\text {unlim }}^{*} \leq \alpha_{\text {lim }}^{*} .
$$




\section{A.5. Proof of Proposition 5}

The proofs are similar to that of $\partial V / \partial \delta<0$ in Proposition 2.

\section{A.6. Proof of Proposition 6}

For Region $i$, an increase in $\alpha_{j}$ is similar to a rise in economic capital. The proof that $\frac{\partial V_{i}}{\partial \alpha_{j}}>0$ is consequently similar to that of $\frac{\partial V}{\partial c}>0$ in Proposition 2. As a result, the proof that $\frac{\partial \alpha_{i}^{* *}}{\partial \alpha_{j}}>0$ is equivalent to that of $\frac{\partial \alpha^{*}}{\partial c}>0$ (Proposition 3). Similarly, using Propositions 5 and 3, we can show that $\frac{\partial \alpha_{i}^{* *}}{\partial \delta_{i}}, \frac{\partial \alpha_{i}^{* *}}{\partial \delta_{j}}$ and $\frac{\partial \alpha_{i}^{* *}}{\partial \theta}$ are negative.

\section{A.7. Proof of Proposition 7}

Let $Z^{k}$ be the dichotomous variable which equals 1 when individual $k, k=1 . . n$, makes a claim. The correlation between risks is given by:

$$
\begin{aligned}
\operatorname{Corr}\left(Z^{k}, Z^{l}\right) & =\frac{\operatorname{Cov}\left(Z^{k}, Z^{l}\right)}{p(1-p)}, \\
& =\frac{\mathbb{P}\left(Z^{k}=1, Z^{l}=1\right)-p^{2}}{p(1-p)}, \\
& =\frac{\left(p_{C}\right)^{2} p^{*}+\left(p_{N}\right)^{2}\left(1-p^{*}\right)-p^{2}}{p(1-p)} .
\end{aligned}
$$

Replacing $p_{N}$ and $p_{C}$ by Equations 15 and 16 yields the correlation as a function of $\delta$ :

$$
\begin{aligned}
\operatorname{Corr}\left(Z^{k}, Z^{l}\right) & =\frac{p}{1-p}\left[\frac{p^{*}+\left(1-p^{*}\right)(1-\delta)}{\left(1-\delta-\delta p^{*}\right)^{2}}-1\right], \\
& =\frac{p}{1-p}[g(\delta)-1] .
\end{aligned}
$$

The derivative of $g$ with respect to $\delta$ is given by:

$$
\frac{d g}{d \delta}=2 p^{*} \times \frac{2-\delta+\delta p^{*}}{1-\delta-\delta p^{*}}
$$

The derivative $\frac{d g}{d \delta}$ is positive for $\delta \in[0 ; 1]$, which implies that $\operatorname{Corr}\left(X^{k}, X^{l}\right)$ is a positive function of $\delta$. Moreover, if $\delta=0$, then $p_{N}=p_{C}=p$ in Equations 15 and 16. In that case, we have $\mathbb{P}\left(Z^{k}=1, Z^{l}=1\right)=p^{2}$ and $\operatorname{Corr}\left(Z^{k}, Z^{l}\right)=0$, which corresponds to the independent case. On the other hand, if $\delta=(1-p) /\left(1-p^{*}\right)$, then $p_{N}=\left(p-p^{*}\right) /\left(1-p^{*}\right)$ and $p_{C}=1$. In that case, we have $\mathbb{P}\left(Z^{k}=1, Z^{l}=1\right)=\left(p^{*}(1-p)^{2}\right) /(1-p *)+p^{2}$ and $\operatorname{Corr}\left(Z^{k}, Z^{l}\right)=\left[p^{*}(1-p)\right] /\left[p\left(1-p^{*}\right)\right]$, which corresponds to the perfectly-dependent case when $p=p^{*}$, i.e. when $\mathbb{P}\left(Z^{k}=1, Z^{l}=1\right)=p$ and $\operatorname{Corr}\left(Z^{k}, Z^{l}\right)=1$. In other words, the lower is $\delta$ the closer are $p_{N}$ and $p_{C}$ to each other and the more independent are the risks.

\section{A.8. Remarks on the externality condition}

Let $\sigma$ represent the standard deviation of individual losses in a portfolio. When insurance contracts are independently and identically distributed, the standard deviation of the average loss $\sigma \sqrt{n} / n$ tends toward zero as the number of policies in the portfolio tends toward infinity. As mentioned in Cummins (2006), this induces a form of increasing returns to scale: the equity capital, or premium rate, required to reach a given insolvency target falls with the size of the risk pool. This phenomenon can be seen as the result of positive externalities in 
consumption. Ceteris paribus, as the size of the portfolio increases, the probability of insolvency falls and each agent enjoys higher expected utility.

We can reach similar conclusions with the mixture model of Section 5. To compute the variance of the total loss $\left(l^{2} \operatorname{Var}(N)\right)$, we need to calculate the variance of $N$. Let $\Theta \in\{$ No Cat, Cat $\}$ denote the occurrence of a natural catastrophe. We have

$$
\operatorname{Var}(N)=\operatorname{Var}(\mathbb{E}[N \mid \Theta])+\mathbb{E}[\operatorname{Var}(N \mid \Theta)],
$$

where $\operatorname{Var}(\mathbb{E}[N \mid \Theta])=n^{2}\left(p_{C}-p_{N}\right)^{2} p^{*}\left[1-p^{*}\right]$ and $\mathbb{E}[\operatorname{Var}(N \mid \Theta)]=n p_{C}\left[1-p_{C}\right] p^{*}+n p_{N}\left[1-p_{N}\right]\left(1-p^{*}\right)$. In other words, we have

$$
\frac{\sqrt{\operatorname{Var}(N)}}{n}=\sqrt{\left(p_{C}-p_{N}\right)^{2} p^{*}\left[1-p^{*}\right]+\frac{p_{C}\left[1-p_{C}\right] p^{*}+p_{N}\left[1-p_{N}\right]\left(1-p^{*}\right)}{n}},
$$

which is a decreasing function of $n$. The result can also be extended to the probability of large events. Conditional on the occurrence of a natural catastrophe, $n X$ has a binomial distribution:

$$
\mathbb{P}_{n}(X \leq x \mid \text { Cat })=\sum_{i=0}^{\lfloor n x\rfloor}\left(\begin{array}{c}
n \\
i
\end{array}\right) p_{C}^{i}\left[1-p_{C}\right]^{n-i}
$$

We obtain that if $x>p_{C}$, then

$$
\mathbb{P}_{n}(X \leq x \mid \text { Cat }) \leq \mathbb{P}_{n+1}(X \leq x \mid \text { Cat }) .
$$

Thus, as in the independent case, the probability that an extreme event occur will fall with $n$. In our theoretical model, this is equivalent to assuming that $\partial F / \partial n>0$ for all $x>x^{*}$. The probability of insolvency then falls with $n$ when $\bar{x}>x^{*}$.

\section{A.9. Strong Nash equilibrium in the one-region model}

Following Konishi et al. (1997) and assuming positive externalities, it is possible to show that there is a unique strong Nash equilibrium in the one-region model which is symmetric. Let $T$ denote the finite set of agents in the economy, with $\operatorname{Card}(T)=n$, and let $A=\{$ Insure, Don't $\}$ be the set of actions available. Each agent $k$ in $T$ chooses an alternative $a^{k}$ from the set $A$. The agents' choice constitutes a strategy profile $\mathbf{a}=\left(a^{1}, a^{2}, \ldots, a^{n}\right)$. The expected utility of agent $k$ is written as $V^{k}=V^{k}\left(a^{k}, \Omega\left(a^{k}, \mathbf{a}\right)\right)$, where $\Omega\left(a^{k}, \mathbf{a}\right)$ represents the set of agents who choose alternative $a^{k}$ under the strategy profile $\mathbf{a}$.

By a positive externality we mean that if agent $k$ is insured, his/her payoff rises as another agent who previously chose "Don't" changes his/her strategy to "Insure". In contrast to Konishi et al. (1997), we assume that the externality condition applies only to insurance, i.e., people who are not insured do not benefit from having an additional member in their group.

Assumption 1 (A Positive Externality from Insurance). For any two agents $k, q \in T$, for any subset of agents $S \subset T$ with $k \in S$ and $q \notin S$, we have

$$
\left\{\begin{array}{l}
V^{k}\left(a^{k}, S\right) \leq V^{k}\left(a^{k}, S \cup\{q\}\right) \text { if } a^{k}=\text { Insure } \\
V^{k}\left(a^{k}, S\right)=V^{k}\left(a^{k}, S \cup\{q\}\right) \text { if } a^{k}=\text { Don't. }
\end{array}\right.
$$

Proposition 8. Under Assumption 1, the one-region model has a strong Nash Equilibrium. This is either (Insure, Insure, $\ldots$, Insure) or (Don't, Don't,$\ldots$, Don't $)$.

Proof. A strong Nash equilibrium is an equilibrium where no group of individuals would be better off by jointly switching their alternatives. Consider first the strategy profile (Don't, Don't, .., Don't). If this is a strong Nash equilibrium, then there is nothing more to be said. Suppose, therefore, that there exists a coalitional deviation that benefits all deviating players, i.e., there is a coalition $S \subset T$ such that $V^{k}$ (insure, $\left.S\right)>V^{k}($ Don't, $T$ ) for all $k \in S$. By Assumption 1 and since the agents are identical, the switch by a player $q \in T \backslash S$ to "Insure" will benefit 
agent $q$ and all the agents in $S$. The repeated use of this argument implies that only (Insure, Insure, .., Insure) can be a strong Nash Equilibrium.

\section{A.10. Strong Nash equilibria in the two-region model}

Following Appendix A.9, let $T_{i}$ denote the finite set of agents in $\operatorname{Region} i$, with $\operatorname{Card}\left(T_{i}\right)=n_{i}, i=1,2$. Each agent $k$ in $T_{i}$ chooses an alternative $a_{i}^{k}$ from $A=\{$ Insure, Don't $\}$. A strategy profile is given by $\mathbf{a}=\left(a_{1}^{1}, a_{1}^{2}, \ldots, a_{1}^{n_{1}}, a_{2}^{1}, a_{2}^{2}, \ldots, a_{2}^{n_{2}}\right)=\left(\mathbf{a}_{1}, \mathbf{a}_{2}\right)$. The expected utility function of agent $k$ is written as $V_{i}^{k}=$ $V_{i}^{k}\left(a_{i}^{k}, \Omega_{i}\left(a_{i}^{k}, \mathbf{a}\right)\right)$, where $\Omega_{i}\left(a_{i}^{k}, \mathbf{a}\right)$ represents the set of agents in Region $i$ who choose alternative $a_{i}^{k}$ under the strategy profile a. We assume that the insurance industry benefits from positive externalities within each region.

Assumption 2 (A Positive Externality from Insurance within each Region). For any two agents $k, q \in T_{i}$, for any subset of agents $S_{i} \subset T_{i}$ with $k \in S_{i}$ and $q \notin S_{i}$, we have

$$
\left\{\begin{array}{l}
V_{i}^{k}\left(a_{i}^{k}, S_{i}\right) \leq V_{i}^{k}\left(a^{k}, S_{i} \cup\{q\}\right) \text { if } a_{i}^{k}=\text { Insure, } \\
V_{i}^{k}\left(a_{i}^{k}, S_{i}\right)=V_{i}^{k}\left(a^{k}, S_{i} \cup\{q\}\right) \text { if } a_{i}^{k}=\text { Don't. }
\end{array}\right.
$$

Proposition 9. Under the externality condition, a strategy profile where agents in the same region do not play the same action cannot be a strong Nash equilibrium.

Proof. Assume that $\mathbf{a}=$ (Don't, Don't, ..., Don't) and that there exists a coalitional deviation in Region $i$ that benefits all deviating players, that is there exists $S_{i} \subset T_{i}$ such that $V_{i}^{k}$ (Insure, $\left.S_{i}\right)>V_{i}^{k}$ (Don't, $\left.T_{i}\right)$ for all $k \in S_{i}$. By Assumption 2, and since the agents are identical, the switch by player $q \in T_{i} \backslash S_{i}$ to "Insure" will benefit agent $q$ and all the agents in $S_{i}$. The repeated use of this argument implies that all players in $T_{i}$ will be better off by choosing "Insure".

Assume now that $\mathbf{a}_{\mathbf{i}}=($ Insure, Insure,$\ldots$, Insure $)$ and $\mathbf{a}_{\mathbf{j}}=($ Don't, Don't,$\ldots$, Don't $)$. Using the previous argument, if there exists a deviation in Region $j$ that benefits all deviating players, then all players in $T_{j}$ will be better off by choosing "Insure". 


\section{References}

Berliner, B. (1982). Limits of Insurability of Risks. Englewood.

Charpentier, A. (2007). Insurability of climate risks. The Geneva Papers on Risk and Insurance Issues and Practice, 33:91-107.

Chiappori, P.-A., Jullien, B., Salanie, B., and Salanie, F. (2006). Asymmetric information in insurance: General testable implications. RAND Journal of Economics, 37:783-798.

Cummins, J. and Danzon, P. (1997). Price, financial quality, and capital flows in insurance markets. Journal of Financial Intermediation, 6:3-38.

Cummins, J. D. (1988). Risk-based premiums for insurance guaranty funds. The Journal of Finance, 43:823-839.

Cummins, J. D. (2006). Should the government provide insurance for catastrophes? Federal Reserve Bank of St. Louis Review, 88:337-380.

Cummins, J. D. and Zi, H. (1998). Comparison to frontier efficiency methods: An application to the US life insurance industry. Journal of Productivity Analysis, 10:131-152.

Denuit, M., Dhaene, J., Goovaerts, M., and Kaas, R. (2005). Actuarial Theory for Dependent Risks: Measures, Orders and Models. Wiley.

Department for Environment, Food and Rural Affairs (DEFRA) (2011). Flood risk and insurance: A roadmap to 2013 and beyond. Final report of the flood insurance working groups - London.

Doherty, N. and Garven, J. (1986). Price regulation in property-liability insurance: A contingent claims approach. Journal of Finance, 41:1031-1050.

Doherty, N. and Schlesinger, H. (1990). Rational insurance purchasing: consideration of contract nonperformance. Quarterly Journal of Economics, 105:245-253.

Einav, L., Finkelstein, A., and Cullen, M. (2010). Estimating welfare in insurance markets using variation in prices. Quarterly Journal of Economics, 125:877-921.

Emons, W. (2001). Imperfect tests and natural insurance monopolies. Journal of Industrial Economics, 49:247-269.

Epermanis, K. and Harrington, S. (2006). Market discipline in property/casualty insurance: Evidence from premium growth surrounding changes in financial strength ratings. Journal of Money, Credit and Banking, 36:1515-1544.

Epple, K. and Schäfer, R. (1996). The transition from monopoly to competition: The case of housing insurance in Baden-Wurttemberg. European Economic Review, 40:1123-1131.

Florida TaxWatch Research Institute (2011). Risk \& reform: A florida taxwatch analysis of florida's property insurance system. Research report. 
Goodspeed, T. J. and Haughwout, A. F. (2012). On the optimal design of disaster insurance in a federation. Economics of Governance, 13:1-27.

IPCC (2007). Contribution of Working Groups I to the Fourth Assessment Report of the Intergovernmental Panel on Climate Change.

Jaffee, D. M. and Russell, T. (1997). Catastrophe insurance, capital markets, and uninsurable risks. Federal Reserve Bank of St. Louis Review, 64:205-230.

Johnson, H. and Stulz, R. (1987). The pricing of options with default risk. Journal of Finance, 42:267280.

Klein, R. (1998). The regulation of catastrophe insurance: An initial overview. Working Paper for The Wharton Catastrophe Risk Project.

Konishi, H., Le Breton, M., and Weber, S. (1997). Pure strategy nash equilibrium in a group formation game with positive externalities. Games and Economic Behavior, 21:161-182.

Kousky, C. (2011). Managing natural catastrophe risk: State insurance programs in the united states. Review of Environmental Economics and Policy, 5:153-171.

Kousky, C. and Cooke, R. (2012). Explaining the failure to insure catastrophic risks. The Geneva Papers, 37:206-227.

Kunreuther, H. (1984). Causes of underinsurance against natural disasters. The Geneva Papers on Risk and Insurance, 31:206-220.

Kunreuther, H. (2001). Mitigation and financial risk management for natural hazards. Geneva Papers on Risk and Insurance - Issues and Practice, 26:276-295.

Kunreuther, H. (2006). Has the time come for comprehensive natural disaster insurance? In Ronald Daniels, D. K. and Kunreuther, H., editors, On Risk and Disaster: Lessons from Hurricane Katrina. Philadelphia: University of Pennsylvania Press.

Litan, R. (2005). Sharing and reducing the financial risks of future 'mega- catastrophes'. Brookings Institute Economics Studies Working Paper, 11.

Matthews, P. B., Sheffield, M., Andre, J., Lafayette, J., Roethen, J., and Dobkin, E. (1999). Insolvency: Will Historic Trends Return? Best's Review-Property-Casualty Insurance Edition.

Mills, E., Lecomte, E., and Peara., A. (2001). U.S. Insurance Industry Perspectives on Global Climate Change.

Rothschild, M. and Stiglitz, J. E. (1970). Increasing risk: A definition. Journal of Economic Theory, 2:225-243.

Rothschild, M. and Stiglitz, J. E. (1976). Equilibrium in competitive insurance markets: An essay on the economics of imperfect information. Quarterly Journal of Economics, 90:630-49.

Schlesinger, H. and v. d. Schulenburg, J. M. G. (1987). Risk aversion and the purchase of risky insurance. Zeitschrift fur Nationalokunomie, 47:309-314. 
Sommer, D. (1996). The impact of firm risk on property-liability insurance prices. Journal of Risk and Insurance, 63:501-514.

Sonnenholzner, M. and Wambach, A. (2004). Oligopoly in insurance markets. In Wiley, J. and Sons, editors, Encyclopedia of Actuarial Science, pages 131-152. New Jersey.

Tapiero, C., Kahane, Y., and Jacque, L. (1986). Insurance premiums and default risk in mutual insurance. Scandinavian Actuarial Journal, pages 82-97.

The Congress of the United States (2002). Federal reinsurance for disasters. A CBO study.

US Government Accountability Office (GAO) (2007). Natural disasters: Public policy options for changing the federal role in natural catastrophe insurance. Report to the Ranking Member, Committee on Financial Services, House of Representatives.

US Government Accountability Office (GAO) (2008). Flood insurance: FEMA's rate-setting process warrants attention. Report to the Ranking Member, Committee on Banking, Housing, and Urban Affairs, U.S. Senate.

Wildasin, D. (2008). Disaster avoidance, disaster relief, and policy coordination in a federation. Working Paper, University of Kentucky.

Zanjani, G. (2002). Pricing and capital allocation in catastrophe insurance. Journal of Financial Economics, 65:283-305.

Zhang, Y. (2008). Economic impact of capital level in an insurance company. Variance, 2,1:39-51. 